\title{
Dinâmica do ecótono floresta-campo no sul do estado do Amazonas no Holoceno, através de estudos isotópicos e fitossociológicos
}

\author{
Elaine VIDOTTO ${ }^{1}$, Luiz Carlos Ruiz PESSENDA ${ }^{1}$, Adauto de Souza RIBEIRO ${ }^{2}$, Hermes Augusto de \\ FREITAS $^{1}$, José Albertino BENDASSOLLI ${ }^{1}$
}

\begin{abstract}
RESUMO
Com o emprego dos isótopos do carbono $\left({ }^{12} \mathrm{C},{ }^{13} \mathrm{C},{ }^{14} \mathrm{C}\right)$ da matéria orgânica do solo (MOS) e das plantas, é apresentado um estudo comparativo entre perfis orgânicos de solos formados em depressões de áreas cobertas por ecossistemas de campos e florestas ao sul do estado do Amazonas, visando o entendimento da dinâmica da paleovegetação. A dinâmica da vegetação atual na região foi avaliada utilizando-se estudos fitossociológicos e caracterizaçôes botânica e isotópica $\left(\delta^{13} \mathrm{C}\right)$ das espécies de plantas presentes em duas bordas floresta-campo. Teores de carbono orgânico total foram superiores nas camadas superficiais no campo, quando comparados com a floresta. Dados de $\delta^{13} \mathrm{C}$ associados à cronologia do ${ }^{14} \mathrm{C}$ indicaram predomínio de plantas $\mathrm{C}_{3}$ no início do Holoceno em ambos os ecótonos. Entre aproximadamente 7.000-3.000 anos AP verificou-se a influência crescente de plantas $\mathrm{C}_{4}$, indicando regressão da floresta com possível presença de um clima mais seco. A partir de aproximadamente 3.000 anos AP os dados sugeriram expansão da floresta provavelmente relacionada ao retorno a um clima mais úmido. A presença de algumas espécies características da borda, como a Sclerolobium paniculatum e Himatanthus sucuuba, nos campos, sugere o atual avanço da floresta sobre os mesmos. Estas espécies estariam sendo as bioindicadoras desse avanço.
\end{abstract}

PALAVRAS-CHAVE

Isótopos do carbono, Dinâmica de vegetação, Holoceno, Fitossociologia, Amazônia.

\section{Vegetation dynamics during the Holocene in a forest-savanna transition, Southern Amazon Basin, based on isotope and phytosociological studies}

\section{ABSTRACT}

This paper presents a comparative study between organic soil horizons formed in depressions located at the forest/savanna boundary in the Southern Amazon Basin. The influence of the paleovegetation dynamics, based on carbon isotope $\left({ }^{12} \mathrm{C},{ }^{13} \mathrm{C}\right.$ and ${ }^{14} \mathrm{C}$ ) data of soil organic matter (SOM) and plants was evaluated, as well as the present vegetation dynamics, inferred from the modern vegetation structure, composition and phytosociology. The uppermost soil horizon in savanna showed higher total carbon content than in forest. ${ }^{13} \mathrm{C}$ and ${ }^{14} \mathrm{C}$ data from soil samples indicated a predominance of $\mathrm{C}_{3}$ plants in the early Holocene. About 7000 to $3000{ }^{14} \mathrm{C}$ yr BP the influence of $\mathrm{C}_{4}$ plants increased, indicating savanna expansion probably related to a drier climate in the region. Since approximately $3000{ }^{14} \mathrm{C}$ yr BP, the carbon isotope data suggest the expansion of forest probably due to a wetter climate. The presence of typical boundary plant species (Sclerolobium paniculatum and Himatanthus sucuuba) in the savanna also suggested present forest expansion.

\section{KEYWORDS}

Carbon isotopes, Vegetation dynamics, Holocene, Phytosociology, Amazonia.

\footnotetext{
${ }^{1}$ Centro de Energia Nuclear na Agricultura, Universidade de São Paulo, Caixa Postal 96, 13416-000, Piracicaba/SP, Brasil. Telefone (19) 3429-4600, Fax (19) 3429-4610. e-mail: evidotto@cena.usp.br, pessenda@cena.usp.br, hfreitas@cena.usp.br, jab@cena.usp.br.

${ }^{2}$ Universidade Federal de Sergipe, Departamento de Biologia, Rodovia Marechal Rondon, s/nº, 49100-000, São Cristóvão/SE, Brasil. (79) 212-6690. e-mail: adautosr@uol.com. br.
} 


\section{INTRODUÇÃO}

Os períodos glaciais e interglaciais que se alternaram sobre as regióes do planeta durante o Quaternário causaram mudanças na temperatura e nível dos oceanos e variações nas quantidades de gelo nas calotas polares. Isso afetou o clima do planeta, principalmente com relação à variação da temperatura e da umidade (Latrubesse \& Franzinelli, 1993). Períodos climáticos mais áridos teriam influenciado na extensão que a floresta amazônica ocupa atualmente (Sioli, 1985).

Estudos palinológicos (Absy \& Van der Hammen, 1976; Absy, 1985; Sanford et al., 1985; Ledru, 1992, 1993; Behling \& Costa, 2000, 2001), geomorfológicos (Servant et al., 1981), sedimentológicos (Suguio et al., 1993; Turcq et al., 1993; Sifeddine et al., 1994, 2001, 2003) e isotópicos (Victoria et al., 1995; Desjardins et al., 1996; Pessenda et al., 1996a,b,c e 1998a, 2001, 2004; Gouveia et al., 1997, 1999, 2002; Freitas et al., 2001) indicam a ocorrência de variaçōes paleoclimáticas na Bacia Amazônica e em outras áreas do Brasil e da América do Sul, durante o Quaternário tardio. Paleoclimas mais secos que o atual, provavelmente, dominou algumas áreas da Bacia Amazônica, favorecendo a substituição da floresta tropical por vegetação do tipo campo.

Estudos indicam que os períodos secos que ocorreram na Bacia Amazônica central e em outras áreas da América do Sul durante o Holoceno, causando mudanças na vegetação da Amazônia, com expansão dos campos, ocorreram entre 8.000-4.000 anos A.P., 4.200-3.500 anos A.P., 2.700-2.000 anos A.P. e 700-400 anos A.P. (Absy et al., 1991, Sifeddine et al., 1994; Gouveia et al., 1997; Pessenda et al., 1998a, b, c; Freitas et al., 2001). Santos et al. (2000) observaram a presença de fragmentos de carvão, em Manaus (AM) no período entre 130 e 2400 anos AP e associaram a presença de fogo a períodos secos na região.

Estudos palinológicos em sedimentos de lagos da Serra dos Carajás (PA) indicaram que em períodos do final do Pleistoceno houve o desaparecimento e o surgimento parcial da floresta. $\mathrm{O}$ aparecimento dos campos, indicativo de períodos mais secos, ocorreu provavelmente entre 60.000-40.000 anos AP, 23.000-11.000 anos AP e 7.500-3.500 anos AP (Sifeddine et al., 1994). Nesta última fase observaram-se restos de vegetais carbonizados, indicando a ocorrência de incêndios freqüentes na região (Turcq et al., 1993, Cordeiro et al., 1997, Elias et al., 2001).

Alguns estudos indicam que, apesar da presença de paleoclimas secos, em algumas regiōes da Amazônia não foi verificado que o campo tenha substituído a vegetação florestal (Valencia, 1993; Bush, 1994; Colinvaux et al., 1996, 2000; Pessenda et al., 1996a, 1998b; Haberle \& Maslin, 1999; Behling et al., 2001; Behling, 2001).
A composição isotópica do carbono $\left({ }^{13} \mathrm{C},{ }^{12} \mathrm{C}\right)$ da $\mathrm{MOS}$ fornece registros da ocorrência de espécies de plantas $\mathrm{C}_{3}$ e/ou $\mathrm{C}_{4}$ nas comunidades de plantas no passado, uma vez que os valores isotópicos não são modificados com o tempo de modo a causar sobreposição nos valores dos ciclos fotossintéticos (Cerling et al., 1989). As plantas do tipo $\mathrm{C}_{3}$ possuem valores isotópicos $\left(\delta^{13} \mathrm{C}\right)$ mais empobrecidos, entre $-20,0 \%$ e $-32,0 \%$, com uma média de $-27,0 \%$, enquanto os valores de $\delta^{13} \mathrm{C}$ das espécies $\mathrm{C}_{4}$ são mais enriquecidos variando entre $-9,0 \%$ e e $-17,0 \%$, com média de $-13,0 \%$. Assim, plantas $\mathrm{C}_{3}$ e $_{4}$ possuem valores de $\delta^{13} \mathrm{C}$ distintos que diferem de, aproximadamente, 14,0\%o entre si (Boutton, 1991).

A literatura indica que estudos de dinâmica floresta-campo no Brasil, utilizando os isótopos do carbono da MOS (matéria orgânica do solo) são bem recentes. Estudos em transecção floresta-campo da Amazônia realizados por Desjardins et al., (1996) indicaram avanços da floresta no Holoceno médio/ superior. Estudos desenvolvidos por Gouveia (1996), Pessenda et al., (1996b, 1998a, 2001) e Freitas et al., (2001) em uma transecção de $250 \mathrm{~km}$ entre as cidades de Porto Velho (RO) e Humaitá (AM), revelaram que durante o Holoceno inferior e médio/superior ocorreram vários períodos de mudanças de vegetação e provavelmente climáticas.

Os métodos convencionais para estudo da dinâmica da vegetação atual utilizam os parâmetros fitossociológicos para medir os estágios sucessionais das comunidades vegetacionais (Glenn-Lewis et al., 1992), que estão relacionados aos padrōes de distribuição, abundância e biomassa (área basal).

Ao sul do estado do Amazonas encontra-se uma regiáo com vegetação de campos e matas abertas denominada de "Campos naturais de Humaitá-Puciari", com uma área de $3418 \mathrm{~km}^{2}$ entre os rios Madeira e Purus. Estes campos, com predomínio de vegetação de gramíneas, encontram-se em contato natural com as florestas da região. Em geral situamse nos platôs, em depressōes que inundam durante as chuvas e secam na estiagem, formando-se camadas orgânicas (tipo turfeiras) de 20 a $30 \mathrm{~cm}$ da superfície do solo. Em adição, de forma menos rotineira, depressões e horizontes orgânicos também são encontrados dentro das florestas em zonas de transição (ecótono) de vegetação. Este aspecto motivou um estudo comparativo entre os solos sob depressōes localizadas na floresta e no campo, através da datação ${ }^{14} \mathrm{C}$, composição isotópica $\left(\delta^{13} \mathrm{C}\right)$ e possíveis influências na dinâmica de (paleo) vegetação.

Pretendeu-se com este trabalho estudar a dinâmica da vegetação atual e passada na região sul da Amazônia, empregando-se técnicas fitossociológicas e os isótopos do carbono $\left(\delta^{13} \mathrm{C},{ }^{14} \mathrm{C}\right)$ da MOS, respectivamente, com inferências climáticas durante o Holoceno 


\section{ÁREA DE ESTUDO}

O estudo foi realizado ao sul do estado do Amazonas,

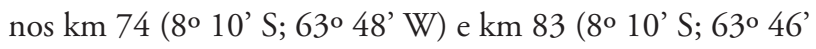
W) ao longo da BR-319, entre as cidades de Porto Velho (RO) e Humaitá (AM) (Figura 1). Na região predomina o clima tropical chuvoso com uma pequena estação seca (tipo Ami), segundo a classificação de Köppen. A média anual de precipitação é de aproximadamente $2.500 \mathrm{~mm}$ e a temperatura média de $25^{\circ} \mathrm{C}$. A precipitação máxima ocorre durante o verão (outubro-março) e o período seco ocorre de junho a agosto. A cobertura pedológica está desenvolvida sobre as rochas terciárias da Formação Solimões, constituída de sedimentos continentais areno-argilosos (Sampaio \& Northfleet, 1973). Os solos dessa região possuem baixa fertilidade natural e são imperfeitamente drenados, apresentando excesso de água durante um período do ano, em geral, na época de maior precipitação pluviométrica (Brasil, 1978). A vegetação predominante é representada pela floresta tropical densa e/ ou aberta (Brasil, 1978), ocorrendo vegetação do tipo campo intercalada por vegetação florestal. Os Campos de Humaitá fazem parte do complexo de vegetação de campos e matas abertas dos Campos Naturais de Humaitá-Puciari, localizados no sul do estado do Amazonas e norte de Rondônia. Esses campos ocupam uma área estimada em $3418 \mathrm{~km}^{2}$, sendo que os Campos de Humaitá ocupam cerca de $18 \%$ do total. Nos campos predominam as gramíneas e as florestas circundantes são formadas por florestas mesófilas baixas, florestas perinifólias altas, palmeiras, castanhais e outras. A

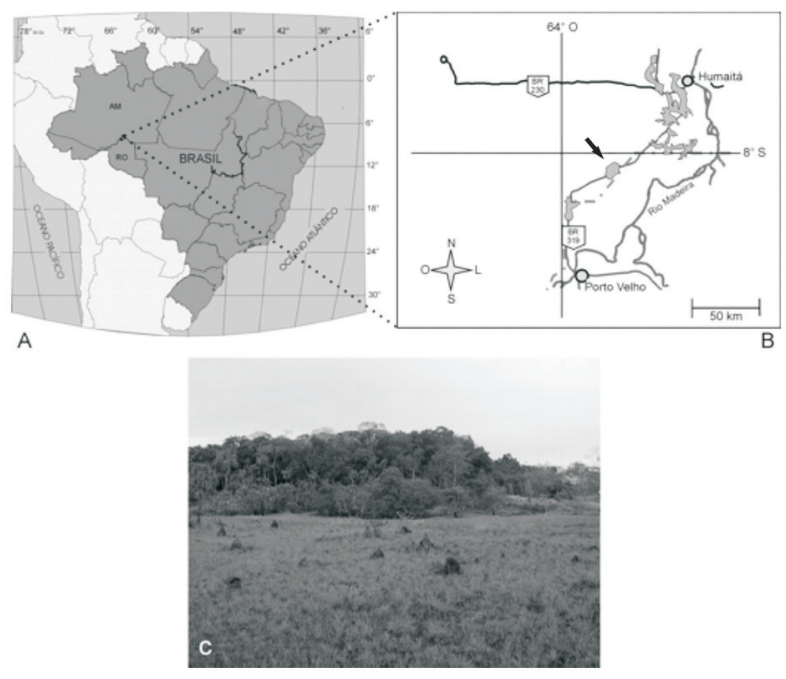

Figura 1 - (A) Mapa do Brasil com a localização da área de estudo (Humaitá, estado do Amazonas - AM e Porto Velho, estado de Rondônia - RO); (B) Localização dos "Campos Naturais de Humaitá" ao longo da BR-319. A seta indica os campos dos km 74 e 83, onde foram realizados os estudos; (C) Foto da transição floresta-campo no km 74. partir de Porto Velho, sentido Humaitá, ao longo da BR 319, há presença de floresta até aproximadamente o $\mathrm{km} 74$ da rodovia, onde surge o primeiro contato com a vegetação de campo natural, que se estende até o $\mathrm{km} \mathrm{83.} \mathrm{Os} \mathrm{demais}$ campos encontram-se localizados aproximadamente entre

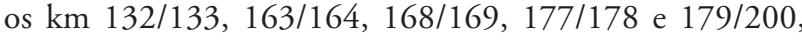
intercalados por floresta natural (Freitas et al., 2001). Para simplificar a redação a floresta tropical densa e/ou aberta e os Campos de Humaitá serão chamados de floresta e campo, respectivamente.

\section{MATERIAL E MÉTODOS}

\section{AMOSTRAGEM DO SOLO}

Os locais de amostragem foram realizados em ecótonos de transição floresta-borda-campo. No km 74 da BR-319 (Figuras 2 e 3 ) as amostras de solos foram coletadas em uma trincheira de $1 \mathrm{~m}$ de profundidade $(\mathrm{HO})$ localizada em uma depressão no campo, com um desnível altimétrico de $2 \mathrm{~m}$ em relação à floresta localizada no platô. Na floresta, a $100 \mathrm{~m}$ do ponto $\mathrm{HO}$, foram feitas 12 tradagens em uma transecção de $30 \mathrm{~m}$ paralela à borda da floresta, onde as amostras coletadas foram identificadas pela simbologia HDF 1 a 12 e a 30 m de HDF 1 coletou-se amostras de uma trincheira de $2 \mathrm{~m}$ de profundidade (THDF). No $\mathrm{km} 83$ foram feitas três tradagens, distantes 50 m entre si, distribuídas numa sequiência floresta-borda-campo. As amostras foram identificadas pela simbologia HF, HB e $\mathrm{HC}$, respectivamente.

Nas coletas em trincheiras foram obtidas amostras com cerca de $5 \mathrm{~kg}$ de solo a cada $10 \mathrm{~cm}$, no sentido das profundidades maiores para as menores, acondicionadas em sacos plásticos e identificadas. Nas coletas por perfuração com trado, de origem holandesa, marca Eijkelkamp, foram obtidas amostras até $250 \mathrm{~cm}$ de profundidade. Os solos foram classificados como Cambissolos.

Em laboratório as amostras de solo foram passadas em peneiras de malha grossa para o destorroamento e, durante o peneiramento, retiraram-se restos de raízes, vegetação, insetos, etc. Após secagem, as amostras foram passadas em peneiras de $2 \mathrm{~mm}$ para a análise granulométrica e de $0,2 \mathrm{~mm}$ para a análise isotópica e do carbono orgânico total. Para a análise do ${ }^{14} \mathrm{C}$ foi extraída a fração humina do solo através de um tratamento ácido-alcalino-ácido (Pessenda et al., 1996a).

As análises granulométricas foram efetuadas no Laboratório de Ciência do Solo da Escola Superior de Agricultura Luiz de Queiroz (ESALQ/USP), através do método do densímetro (Kiehl, 1979) e os resultados foram expressos em porcentagem de argila. Foram analisados somente os solos coletados no $\mathrm{km} 74$.

A determinação do carbono orgânico total (COT) e do 
$\delta^{13} \mathrm{C}$ foi feita no Laboratório de Isótopos Estáveis - CENA/ USP, em um espectrômetro de massa acoplado a um analisador elementar ANCA-SL, Europa Scientific. Os resultados de teor de carbono foram reportados como carbono orgânico total e expressos em porcentagem de peso seco. Os resultados da análise isotópica foram expressos em unidade de $\delta(\%)$, determinada em relação ao padrão internacional PDB e referem-se à média de duas determinaçôes, com precisão de $\pm 0,2 \%$.

As dataçôes ${ }^{14} \mathrm{C}$ da fração humina foram feitas através da técnica AMS (Accelerator Mass Spectrometry) obtidas no Laboratório Isotrace, Universidade de Waterloo, Canadá. A idade ${ }^{14} \mathrm{C}$ é expressa em anos AP (antes do presente), normalizada a $-25,0 \%$ o (PDB), sendo presente o ano de 1950.

\section{AMOSTRAGEM DA VEGETAÇÃO}

Foram realizadas amostragens para três tipos de análise: (1) isotópica: coletaram-se amostras de plantas para a determinação do $\delta^{13} \mathrm{C}$ foliar. As amostras foram lavadas com água destilada, secas em estufa a $50^{\circ} \mathrm{C}$, moídas e encaminhadas

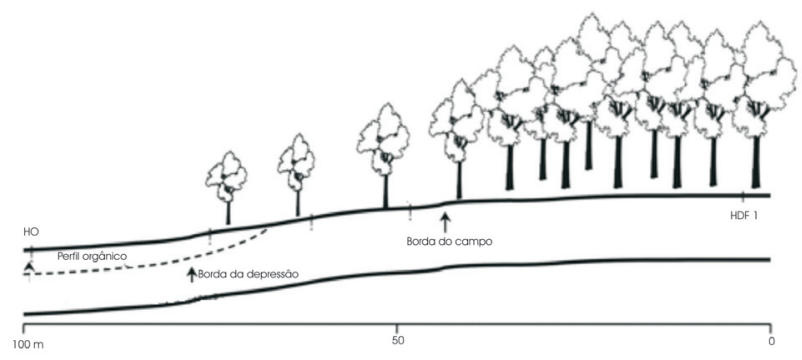

Figura 2 - Localização dos pontos de amostragem no km 74.

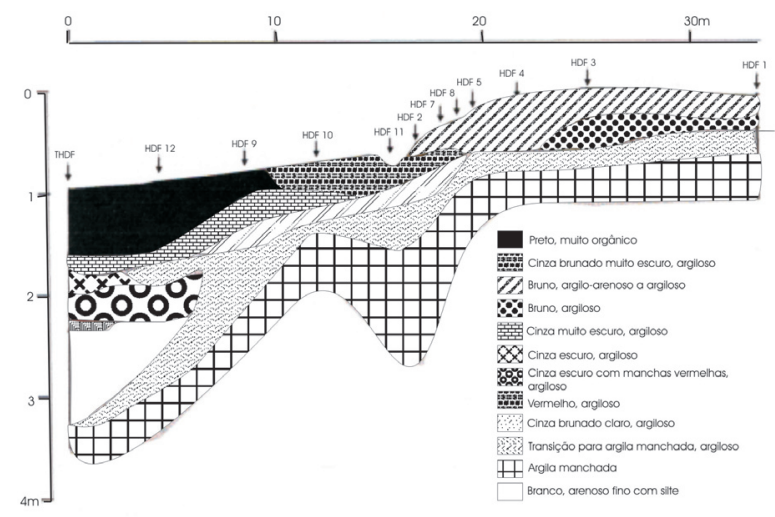

Figura 3 - Localização dos pontos de amostragem na floresta do $\mathrm{km} \mathrm{74}$; transecção paralela à borda. ao Laboratório de Isótopos Estáveis do CENA/USP; (2) florística: para caracterizar a composição das espécies das diferentes fisionomias (floresta, borda e campo). As espécies inventariadas foram coletadas e identificadas; (3) estrutural: para obtenção de parâmetros quantitativos que auxiliam na caracterização da vegetação.

A revisão das nomenclaturas dos táxons foi feita no compêndio das plantas vasculares de Ribeiro et al., (1999); New York Botanical Garden, (2003) e Missouri Botanical Garden - W/3T, (2003).

Para a amostragem da vegetação arbórea utilizou-se o método Ponto Quadrante (Cottam \& Curtis, 1956), na floresta e na borda. No km 74 foram demarcados 26 pontos na floresta e 10 pontos na borda e no $\mathrm{km} \mathrm{83,10}$ pontos na floresta e 10 pontos na borda. Foram inventariadas as árvores com circunferência na altura do peito (CAP) maior ou igual a $10 \mathrm{~cm}$. Em cada quadrante foram anotadas quatro árvores mais próximas ao ponto, assim como, o seu vizinho mais próximo, totalizando oito árvores por quadrante. Foram tomadas as medidas da CAP e da altura das árvores.

Para a análise da estrutura da vegetação seguiram-se as recomendaçôes de Brower et al., (1998) e foram analisados os parâmetros densidade (D), área basal (G), densidade relativa (DR), frequêencia relativa (FR), dominância relativa (DoR) e índice de valor de importância (IVI).

Para o levantamento da composição florística da vegetação herbácea do campo utilizou-se o método Ponto Contato (Whitman \& Siggeirsson, 1954). Foram demarcados quinze pontos no $\mathrm{km} 74$ e dez pontos no $\mathrm{km} 83$.

No campo do $\mathrm{km} 74$ foram amostrados os indivíduos presentes em dezessete "aglomerados arbóreos" distantes cerca de 20 a $80 \mathrm{~m}$ da borda da floresta.

\section{RESULTADOS E DISCUSSÃO}

\section{TEORES DE ARGILA E CARBONO ORGÂNICO TOTAL DOS SOLOS}

Os solos estudados apresentaram principalmente textura argilosa (35 a 59\% de argila) e muito argilosa (60\% de argila ou superior) (Figura 4).

No perfil HO o teor de argila variou entre 42 e $74 \%$, sendo classificado como muito argiloso entre 10 e $40 \mathrm{~cm}$ e, 50 e 100 $\mathrm{cm}$. As camadas $0-10 \mathrm{~cm}$ e $40-50 \mathrm{~cm}$ foram classificadas como argilosas (42\% e 56\%, respectivamente).

$\mathrm{O}$ solo THDF apresentou teores de argila variando entre 30 e $89 \%$, sendo classificado como médio-argiloso na camada 0-10 cm e muito argiloso no intervalo entre 20 e $110 \mathrm{~cm}$. $\mathrm{Na}$ camada $190-200 \mathrm{~cm}$ o solo foi classificado como argiloso (40\%). Os solos HDF 1 e 2 apresentaram teores de argila entre 36 e $55 \%$ e foram classificados como argilosos. Os teores dos solos HDF 3, 4, 5, 9, 10 e 11 variaram entre 25 e 49\% 
e foram classificados como médio argilosos ou argilosos. $\mathrm{O}$ solo HDF 12 foi classificado como médio-argiloso e muito argiloso, com teores variando entre 26 e $62 \%$.

Em geral, os solos $\mathrm{HO}$ e THDF apresentaram os maiores teores de argila, com exceção da camada $0-10 \mathrm{~cm}$ do solo THDF que apresentou teor de $30 \%$. Entre as profundidades 60-70 cm e 100-110 cm do solo THDF foram observados os maiores teores, $81-89 \%$. Condição similar foi observada por Rosolen (2000) na região.

No km 74 a concentração de carbono orgânico total decresceu da superfície para maiores profundidades em todos os solos analisados (Figura 4). No campo (HO) os primeiros $50 \mathrm{~cm}$ apresentaram-se com elevado teor de carbono, sendo de $8,32 \%$ na camada $0-10 \mathrm{~cm}$ e $3,07 \%$ na camada $40-50 \mathrm{~cm}$. Neste ponto, localizado à jusante de uma depressão, o alto teor de carbono pode estar relacionado com o fato desta depressão permanecer inundada durante o período das chuvas (aproximadamente 6 meses) fazendo com que haja uma maior preservação da matéria orgânica. Entre 50 e $100 \mathrm{~cm}$ os teores de carbono ficaram entre $1,65 \%$ e $0,49 \%$.

$\mathrm{Na}$ floresta os solos que apresentaram maiores teores de carbono na camada $0-10 \mathrm{~cm}$ foram HDF 12 (6,15\%), HDF $9(5,61 \%)$, THDF (5,75\%) e HDF 10 (4,75\%). Esses pontos localizam-se em depressōes e o alto teor de carbono pode estar relacionado com o acúmulo e preservação da matéria orgânica em função do desnível altimétrico e inundação do local durante os períodos chuvosos. À medida que se afastou desses pontos, à montante, os teores diminuíram, ficando entre $1,02 \%$ (HDF 7) e 3,56\% (HDF 1) na camada $0-10 \mathrm{~cm}$. Caracterizou-se para os solos um decréscimo do teor de carbono para maiores profundidades, que se apresentaram similares aos encontrados na mesma região (Pessenda et al., 2001; Rosolen, 2000). Nas profundidades entre 50 e $100 \mathrm{~cm}$ os teores de carbono variaram entre $4,39 \%$ (HDF 12) e $0,44 \%$ (HDF 11) aos $40-50 \mathrm{~cm}$, e entre $0,17 \%$ (HDF 10) e $0,93 \%$ (HDF 12) aos $90-100 \mathrm{~cm}$. Entre 100 e $200 \mathrm{~cm}$ os teores ficaram entre $0,03 \%$ e $1,27 \%$.

A Figura 4 indica que os maiores teores de carbono orgânico total obtidos para os solos HO, THDF e HDF, desde a superfície até aproximadamente $100 \mathrm{~cm}$, estiveram relacionados com os maiores teores de argila para os mesmos solos.

No km 83 também se observou decréscimo do teor de carbono da superfície para maiores profundidades (Figura 5). Nas camadas superficiais $(0-10 \mathrm{~cm})$ observou-se um valor de $1,65 \%$ na floresta, $2,62 \%$ na borda e $2,2 \%$ no campo. Neste local os solos da borda e do campo apresentaram maiores teores de carbono do que a floresta nas camadas superficiais.

A tendência de decréscimo do teor de carbono orgânico total da superfície para profundidades maiores também foi observada nos solos desta e de outras regiōes da Amazônia (Gouveia, 1996; Pessenda et al., 1998a,b,c, 2001; Rosolen, 2000).

\section{DATAÇÃO POR ${ }^{14} \mathrm{C}$ DA MOS}

As dataçoes por ${ }^{14} \mathrm{C}$ variaram entre 3.290 e 6.770 anos AP (Tabela 1). No solo localizado sob vegetação de campo (HO) no km 79 foram obtidas as dataçôes de 3.730 anos $\mathrm{AP} \pm 100$ na camada $40-50 \mathrm{~cm}$ e 6.770 anos $\mathrm{AP} \pm 60$ na camada $90-100$ $\mathrm{cm}$. A datação de 3.730 anos AP foi concordante com a obtida por Pessenda et al., (2001) em amostras de carvão coletadas, à mesma profundidade, neste local. Dataçôes realizadas em horizonte orgânico, rico em matéria orgânica, da depressão, indicaram que a matéria orgânica foi moderna (> 100\% em porcentagem de carbono moderno) para a amostra de superfície $(0-10 \mathrm{~cm})$ e de 1.650 anos AP para a amostra de 20-30 cm de profundidade (Pessenda et al., 2001).

Nos solos sob vegetação de floresta (THDF) as datações indicaram o período entre 3.290 anos $\mathrm{AP} \pm 70$ na camada $40-50 \mathrm{~cm}$ a 6.560 anos $\mathrm{AP} \pm 100$ na camada $100-110 \mathrm{~cm}$.

Os resultados para a camada $40-50 \mathrm{~cm}$ e a aproximadamente $100 \mathrm{~cm}$ de profundidade dos perfis HO e THDF foram contemporâneos, indicando que não houve diferença significativa no período de incorporação da matéria orgânica nas depressões no campo (HO) e na floresta (THDF).

Os resultados evidenciaram um crescimento regular na datação da fração humina da MOS com o aumento da profundidade dos solos. Resultados similares foram obtidos em outros locais da Bacia Amazônica e do Brasil, com valores de aproximadamente 5.000-6.000 anos AP para as camadas $90-100 \mathrm{~cm}$ e $10.000-12.000$ anos AP a dois metros de profundidade (Pessenda et al., 1996a,b, 1998a,b,c, 2004; Gouveia et al., 1997, 1999, 2002; Freitas, 1999; Freitas et al., 2001; Gouveia \& Pessenda, 2000).

Tabela 1 - Datação 14C, por AMS, da fração humina das amostras de solo.

\begin{tabular}{llll}
\hline No Laboratório & Profundidade $(\mathrm{cm})$ & $\%$ Carbono Moderno & Idade ${ }^{14} \mathrm{C}($ anos AP) \\
\hline T0 10927 & H0 40-50 & $62,89 \pm 0,82$ & $3730 \pm 100$ \\
T0 10928 & H0 90-100 & $43,05 \pm 0,32$ & $6770 \pm 60$ \\
T0 11124 & THDF 40-50 & $66,37 \pm 0,6$ & $3290 \pm 70$ \\
T0 11125 & THDF $100-110$ & $44,17 \pm 0,53$ & $6560 \pm 100$ \\
\hline
\end{tabular}

Datação ${ }^{14} \mathrm{C}$, por AMS, da fração humina das amostras de solo.

\section{ANÁLISE ISOTÓPICA $\left(\delta^{13} \mathrm{C}\right)$ DA MOS}

\section{KM 74}

No solo localizado na depressão sob vegetação de campo (HO) o valor de $\delta^{13} \mathrm{C}$ de $-22,0 \%$ o para a camada superficial $\left(0-10 \mathrm{~cm}\right.$ ) indicou uma mistura de plantas $\mathrm{C}_{3}$ e $\mathrm{C}_{4}$ (Figura 4). 
Tabela 2 - Valores de $\delta^{13} \mathrm{C}$ das plantas coletadas na floresta, na borda e no campo do $\mathrm{km} 74$.

\begin{tabular}{|c|c|c|c|c|}
\hline \multirow{2}{*}{ Espécie } & \multirow{2}{*}{ Família } & \multicolumn{3}{|c|}{$\delta^{13} \mathrm{C}(\% \circ)$} \\
\hline & & Floresta & Borda & Campo \\
\hline Heliconia psittacorum & Heliconiaceae & $-34,3$ & & \\
\hline Hemicrepidospermum sp & Burseraceae & $-34,0$ & & \\
\hline Ischnosiphon sp & Marantaceae & $-33,9$ & & \\
\hline Mauritiella armata & Arecaceae & $-29,3$ & & \\
\hline Oenocarpus bacaba & Arecaceae & $-31,4$ & & \\
\hline Oenocarpus bataua & Arecaceae & $-31,3$ & & \\
\hline Protium sp & Burseraceae & $-34,1$ & & \\
\hline Socratea exorrhiza & Arecaceae & $-31,4$ & & \\
\hline Alibertia edulis & Rubiaceae & & $-30,6$ & \\
\hline Ananas ananassoides & Bromeliaceae & & $-16,1$ & \\
\hline Annona sp1 & Annonaceae & & $-31,0$ & \\
\hline Byrsonima sp1 & Malpighiaceae & & $-27,8$ & \\
\hline Caraipa savannarum & Clusiaceae & & $-28,8$ & \\
\hline Eugenia sp & Myrtaceae & & $-33,1$ & \\
\hline Hibiscus furcellatus & Malvaceae & & $-31,8$ & \\
\hline Himatanthus sucuuba & Apocynaceae & & $-28,4$ & \\
\hline Licania sp & Chrysobalanaceae & & $-30,2$ & \\
\hline Mabea subsessilis & Euphorbiaceae & & $-29,2$ & \\
\hline Miconia tiliifolia & Melastomataceae & & $-33,0$ & \\
\hline Monotagma sp & Marantaceae & & $-29,6$ & \\
\hline Pouteria guianensis & Sapotaceae & & $-31,4$ & \\
\hline Pouteria sp & Sapotaceae & & $-30,5$ & \\
\hline Scleria aff reflexa & Cyperaceae & & $-33,8$ & \\
\hline Selaginella fragilis & Selaginelaceae & & $-32,0$ & \\
\hline Tibouchina aspera & Melastomataceae & & $-33,5$ & \\
\hline Trema micrantha & Ulmaceae & & $-31,6$ & \\
\hline Vismia guianensis & Clusiaceae & & $-30,9$ & \\
\hline Xylopia aromatica & Annonaceae & & $-31,0$ & \\
\hline Andropogon bicornis & Poaceae & & & $-13,1$ \\
\hline $\begin{array}{l}\text { Andropogon } \\
\text { leucostachyus }\end{array}$ & Poaceae & & & $-11,8$ \\
\hline Andropogon sp & Poaceae & & & $-11,7$ \\
\hline Andropogon sp2 & Poaceae & & & $-12,6$ \\
\hline Aristida capillacea & Poaceae & & & $-26,7$ \\
\hline Cyperus sp & Cyperaceae & & & $-12,4$ \\
\hline Fimbristylis sp & Cyperaceae & & & $-12,7$ \\
\hline Kyllinga sp & Cyperaceae & & & $-11,8$ \\
\hline Panicum parvifolium & Poaceae & & & $-28,8$ \\
\hline Panicum sp1 & Poaceae & & & $-26,9$ \\
\hline Panicum sp2 & Poaceae & & & $-28,3$ \\
\hline Panicum sp3 & Poaceae & & & $-28,0$ \\
\hline Paspalum sp1 & Poaceae & & & $-12,7$ \\
\hline Rhynchospora sp & Cyperaceae & & & $-28,5$ \\
\hline
\end{tabular}

Foram encontradas, neste local, cinco espécies de gramíneas $\mathrm{C}_{3}$, quatro pertencentes ao gênero Panicum com $\delta^{13} \mathrm{C}$ de aproximadamente $-28,0 \%$ e a Aristida capillacea Lam. com $\delta^{13} \mathrm{C}$ de $-26,7 \%$ o, juntamente com outras cinco espécies de gramíneas $\mathrm{C}_{4}$, que possuem valores de $\delta^{13} \mathrm{C}$ mais enriquecidos, entre $-11,7 \%$ e e $-13,1 \%$ o (Tabela 2 ).

Entre as camadas 10 e $100 \mathrm{~cm}$ observou-se um enriquecimento isotópico, onde os valores de $\delta^{13} \mathrm{C}$ ficaram entre $-20,3 \%$ e $-19,6 \%$, indicando influência de plantas $\mathrm{C}_{4}$ entre 6770 anos A.P. até, pelo menos, 1650 anos A.P. Pessenda et al. (2001) observaram que houve uma significativa mudança de vegetação nesta área durante o Holoceno, onde foram observados valores similares de $\delta^{13} \mathrm{C}$, entre $-14,0 \%$ o e - $19,0 \%$, no intervalo entre 30 a $130 \mathrm{~cm}$, indicando uma possível regressão da floresta, no local com predomínio de plantas $\mathrm{C}_{4}$. Dataçóes de amostras de fragmentos de carvão a uma profundidade de $50 \mathrm{~cm}$ indicaram período entre 3.800 4.700 anos AP, concordante com a datação da fração humina encontrada neste trabalho, para a mesma profundidade. Com base nos dados de $\delta^{13} \mathrm{C}$ de aproximadamente $-26,0 \%$ na profundidade de $200 \mathrm{~cm}$, obtida por Pessenda et al. (2001) em solos desta área e cerca de 20 dataçóes ${ }^{14} \mathrm{C}$ deste e outros trabalhos na região (Gouveia et al, 1997; Pessenda et al., 1998a; 1998b; 1998c; Freitas et al., 2001) verificou-se que no período de 10.000-12.000 anos AP a área foi coberta por vegetação $C_{3}$, provavelmente floresta. Aproximadamente entre 7.000 e 4.000 anos AP, os dados mostraram influência de plantas $\mathrm{C}_{4}$, indicando uma regressão da floresta associada a um provável clima mais seco que o atual. As dataçōes ${ }^{14} \mathrm{C}$ indicaram que a matéria orgânica, originada de plantas $\mathrm{C}_{3} \mathrm{e}$ $\mathrm{C}_{4}$, vem sendo incorporada, pelo menos, nos últimos 7.000 anos nesta depressão (vidotto, 2003). Esses dados são similares aos encontrados por Pessenda et al. (2001) na região.

Os valores de $\delta^{13} \mathrm{C}$ do solo THDF, localizado numa depressão na floresta, apresentaram-se característicos de plantas $\mathrm{C}_{3}$ em todo o perfil (Figura 4). O valor $-26,0 \%$ o observado na camada $0-10 \mathrm{~cm}$ foi característico da atual cobertura vegetal (floresta). No intervalo entre 40 e $200 \mathrm{~cm}$ os valores ficaram entre $-22,9 \%$ e $-24,7 \%$ e na profundidade $240-250 \mathrm{~cm}$ foi encontrado valor de $-25,0 \%$, enriquecimento em ${ }^{13} \mathrm{C}$ que não indica mudança de vegetação de plantas $\mathrm{C}_{3}$ para $\mathrm{C}_{4}$. Os resultados da datação ${ }^{14} \mathrm{C}$ da camada $40-50 \mathrm{~cm}$ e $100-110 \mathrm{~cm}$ indicaram o período de 3.290 anos $\mathrm{AP} \pm 70$ e 6.560 anos $A P \pm 100$, respectivamente. Provavelmente neste intervalo entre 6.500 e 3.300 anos AP ocorreu no local uma vegetação arbórea menos densa do que a atual, ou uma mistura de plantas $\mathrm{C}_{3} \mathrm{e} \mathrm{C}_{4}$, com possível predomínio das primeiras, não indicando troca significativa de vegetação. Por este ponto estar localizado no centro de uma depressão, pode-se considerar a probabilidade de uma significativa entrada de matéria orgânica de origem $\mathrm{C}_{3}$, transportada de áreas mais altas e preservadas na depressão. É possível, também, que uma vegetação específica de condições hidromórficas, por exemplo, gramíneas do tipo $\mathrm{C}_{3}$, tenham permanecido na depressão desde o início até o fim do período seco, que corresponde à regressão florestal. 
Nos demais pontos da transecção, HDF 1 a 12, que estão em locais mais elevados, pode-se observar variações isotópicas, com provável troca de vegetação ao longo do perfil (Figura 4). Todos os valores de $\delta^{13} \mathrm{C}$ nas camadas superficiais (5-20 $\mathrm{cm}$ ) foram característicos da vegetação de cobertura (floresta), entre $-24,4 \%$ o (HDF 1) e -28,8\%o (HDF 2). A partir de $20 \mathrm{~cm}$ se observa um enriquecimento isotópico até a camada $100 \mathrm{~cm}$, atingindo valores típicos de MOS com influência de plantas $\mathrm{C}_{4}$ (cerca de $-18,8 \%$ ), provavelmente presentes em períodos passados, indicando a regressão da floresta e expansão do campo, devido à possível presença de um clima mais seco que o atual, que atingiu o sul do estado do Amazonas, há cerca de 7.000 anos AP (Gouveia et al., 1997; Freitas et al., 2001). Os solos que apresentaram enriquecimento mais significativo foram HDF $1,7,8$ e $9(-18,8 \%,-19,4 \%$, $-21,2 \%$ e $-21,8 \%$, respectivamente) na camada $40-50 \mathrm{~cm}$; HDF $9-21,8 \%$ ) na camada $80-90 \mathrm{~cm}$; HDF 1,10 e 12 $(-22,8 \%$ o, $-20,9 \%$ e $-21,2 \%$, respectivamente) na camada $90-100 \mathrm{~cm}$. Com exceção dos pontos HDF 9 e 12, os demais onde foi observado maior enriquecimento isotópico estavam localizados à montante da depressão. A partir de $110 \mathrm{~cm}$ até as camadas mais profundas os valores de $\delta^{13} \mathrm{C}$ apresentaram-se mais empobrecidos isotopicamente, ficando entre $-24,1 \%$ o $-25,9 \%$, caracterizando maior influência de plantas $C_{3}$.

Com base nos resultados isotópicos $\left(\delta^{13} \mathrm{C}\right)$ e nas datações ${ }^{14} \mathrm{C}$, aproximadamente desde o Pleistoceno superior até o Holoceno inferior, uma vegetação arbórea predominou no $\mathrm{km} 74$. Posteriormente, desde aproximadamente 7.000 anos $\mathrm{AP}$ até cerca de 3.000 anos $\mathrm{AP}$, houve expansão do campo, talvez relacionado com a presença de um clima seco. De 3.000 anos AP até o presente os dados isotópicos indicaram um empobrecimento do ${ }^{13} \mathrm{C}$ do solo, que foram interpretados como uma expansão da floresta sobre o campo, devido ao retorno a um clima úmido e provavelmente similar ao atual (Vidotto, 2003).

Gouveia et al. (1997), Pessenda et al. (1998a, 1998c, 2001) e Freitas et al. (2001), empregando isótopos do carbono do solo em uma transecção de $250 \mathrm{~km}$ em um ecótono floresta-campo na região de Humaitá verificaram que no período de 17.000 a 9.000 anos AP uma vegetação predominantemente florestal recobria toda a paisagem. A partir de aproximadamente 9.000-8.000 anos AP até aproximadamente 3.000 anos AP, vários locais da transecção foram substituídos por vegetação de campo (gramíneas $\mathrm{C}_{4}$ ), provavelmente devido à presença de clima seco. Desde aproximadamente 3.000 anos AP até o presente os dados isotópicos indicaram predomínio de plantas $\mathrm{C}_{3}$, que foram relacionadas com o retorno a um clima úmido e expansão da floresta, como observado atualmente. Aspectos similares para os mesmos períodos foram observados nos estados de Rondônia (Pessenda et al., 1998d), Roraima (Desjardins et al., 1996) e Pará (Sifeddine et al., 1994).

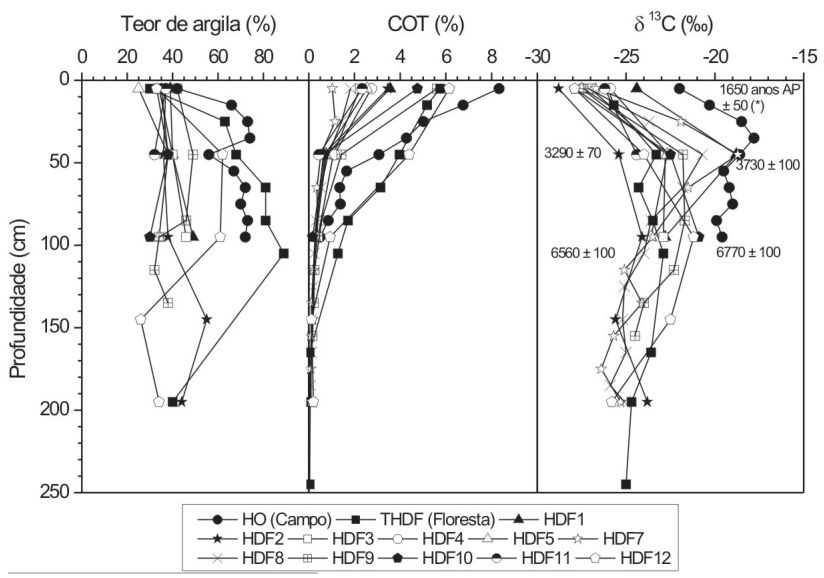

Figura 4 - Teor de argila, $\mathrm{COT}, \delta^{13} \mathrm{C}$ e datação ${ }^{14} \mathrm{C}$ em relação à profundidade dos solos localizados no km 74. ( $\left.{ }^{*}\right)$ Datação obtida por Pessenda et al., 2001, na camada $20-30 \mathrm{~cm}$.

\section{KM 83}

No solo HF (floresta) o valor de $\delta^{13} \mathrm{C}$ de $-25,3 \%$, na camada $0-10 \mathrm{~cm}$, foi característico da vegetação florestal de cobertura (Figura 5). A partir de $10 \mathrm{~cm}$ até $80 \mathrm{~cm}$ observouse um enriquecimento isotópico $(-21,6 \%$ a $-17,7 \%$ ), caracterizando influência de plantas $\mathrm{C}_{4}$. Com base nas datações ${ }^{14} \mathrm{C}$ obtidas por Freitas et al. (2001) para perfis de solo em áreas de florestas da região, estima-se que entre aproximadamente 9.000 e 3.000 anos AP a área atualmente coberta por vegetação de floresta (plantas do tipo $\mathrm{C}_{3}$ ) esteve ocupada, predominantemente, por gramíneas do tipo $\mathrm{C}_{4}$ Entre as camadas $90-100 \mathrm{~cm}(-21,1 \%)$ e $120-130 \mathrm{~cm}$ $\left(-23,1 \%\right.$ ) observaram-se valores de $\delta^{13} \mathrm{C}$ mais empobrecidos, característicos de uma provável mistura de plantas $\mathrm{C}_{3}$ e $\mathrm{C}_{4}$, com predomínio das primeiras.

$\mathrm{Na}$ borda entre floresta e campo (HB) o valor do $\delta^{13} \mathrm{C}$ na camada superficial foi $-25,9 \%$ (Figura 5). Entre as camadas $40-50 \mathrm{~cm}$ e $60-70 \mathrm{~cm}$ houve um empobrecimento isotópico de $7 \%$, em relação a camada imediatamente acima, onde se observou um valor de $\delta^{13} \mathrm{C}$ de $-23,8 \%$, provavelmente relacionado a material orgânico proveniente de camadas superficiais devido a efeito de pedoturbação (Boulet $e t$ al, 1995). Observa-se neste intervalo um teor de carbono bem mais elevado $(1,05 \%)$ que nas camadas imediatamente superior e inferior. A partir da camada $60-70 \mathrm{~cm}$ até as mais profundas, os valores entre $-20,2 \%$ a $-24,6 \%$ indicaram uma mistura de plantas $\mathrm{C}_{3}$ e $\mathrm{C}_{4}$, com provável predomínio das primeiras.

No campo (HC) o valor de $\delta^{13} \mathrm{C}$ da MOS na camada superficial $(0-10 \mathrm{~cm})-13,4 \%$ o caracterizou a vegetação de cobertura predominante na área, ou seja, gramíneas do tipo $\mathrm{C}_{4}$ (Figura 5) A partir da camada $60-70 \mathrm{~cm}$ até as camadas mais 


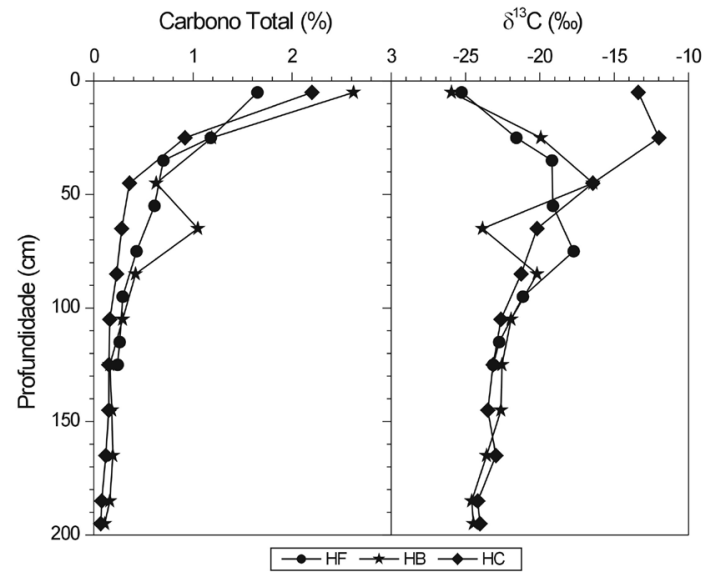

Figura 5 - Teor de carbono orgânico total e $\delta 13 \mathrm{C}$ em relação à profundidade dos solos localizados no km 83.

profundas observou-se um empobrecimento isotópico, com valores de $-24,0 \%$ na camada $190-200 \mathrm{~cm}$. Essa tendência de empobrecimento isotópico com a profundidade está associada à predominância de vegetação do tipo $\mathrm{C}_{3}$ em períodos passados. Mudança similar de vegetação foi observada por Freitas et al., (2001) na mesma região no $\mathrm{km} 82$.

\section{ANÁLISE DA COMPOSIÇÃO FLORÍSTICA E ESTRUTURAL DA VEGETAÇÃO E PARÂMETROS FITOSSOCIOLÓGICOS}

\section{COMPOSIÇÃO FLORÍSTICA E ESTRUTURAL}

No km 74 registraram-se a ocorrência de 131 espécies e 94 gêneros distribuídos em 40 famílias (Tabela 3). As famílias predominantes em número de espécies foram: Fabaceae (12 espécies), Arecaceae (11), Poaceae (9), Annonaceae (7), Melastomataceae (6), Cyperaceae (6) e Vochysiaceae (6). A forma de vida caracterizou-se pela presença de 93 espécies arbóreas, 21 espécies de ervas, 12 arbustivas, 3 lianas e 2 epífitas.

$\mathrm{Na}$ floresta as espécies predominantes no estrato arbóreo foram: Euterpe precatoria (18 indivíduos), Vismia guianensis (17), Orbignya speciosa (11), Oenocarpus bacaba (10) e Mabea subsessilis (9). Estas espécies não foram encontradas no levantamento efetuado na borda do ecótono. A densidade arbórea foi estimada em 930 ind/ha e a área basal em 19,2 m²/ ha. Os valores médios obtidos para os parâmetros altura da copa, CAP e distância média entre as árvores foram de 14,83 $\pm 6,48 \mathrm{~m}$ ( \pm 1 desvio padrão), $65 \pm 43 \mathrm{~cm} \mathrm{e} \mathrm{3,31 \pm 1,68} \mathrm{m,}$ respectivamente.

$\mathrm{Na}$ borda as espécies predominantes foram: Sclerolobium paniculatum (9), Himatanthus sucuuba (7) e Mabea caudata (5). A densidade arbórea foi estimada em 1260 ind/ha e a área basal em 11,3 $\mathrm{m}^{2} / \mathrm{ha}$. A altura média das árvores foi de
$10,36 \pm 2,72 \mathrm{~m}$, CAP médio de $53 \pm 27 \mathrm{~cm}$ e distância média de $2,82 \pm 1,25 \mathrm{~m}$.

No levantamento efetuado nos dezessete "aglomerados arbóreos" localizados no campo as espécies que apresentaram maior número de indivíduos foram: Himatanthus sucuuba (37), Sclerolobium paniculatum (31) e Caraipa savannarum (25). As médias das alturas das árvores e da CAP foram de $10,12 \pm 6,17 \mathrm{~m}$ e 47,82 $\pm 19,19 \mathrm{~cm}$, respectivamente. A densidade foi estimada em 430 ind/ha e a área basal em 9,2 $\mathrm{m}^{2} /$ ha.

No campo o estrato herbáceo foi caracterizado pela presença de gramíneas e ciperáceas, onde predominaram as gramíneas dos gêneros Andropogon (43\%) e Paspalum (34\%).

Os resultados de $\delta^{13} \mathrm{C}$ das espécies arbóreas da floresta apresentaram valores entre $-29,3 \%$ e $-34,1 \%$ o (Tabela 2 ), que foram concordantes com os valores $\delta^{13} \mathrm{C}$ encontrados nas camadas superficiais dos solos amostrados sob vegetação de floresta (Figura 4). Na borda, 90\% das espécies analisadas apresentaram $\delta^{13} \mathrm{C}$ entre $-27,8 \%$ e $-33,8 \%$, característicos de vegetação $\mathrm{C}_{3}$ e $10 \%$ entre $-13,2 \%$ e $-16,1 \%$, característicos de vegetação $\mathrm{C}_{4}$ (Tabela 2 ). No campo a maioria das gramíneas apresentou valor de $\delta^{13} \mathrm{C}$ característico de vegetação $\mathrm{C}_{4}$, entre $-12,8 \%$ e $-13,5 \%$, com exceção das gramíneas do gênero Panicum (aproximadamente -28,0\%o) e Aristida capillacea $\left(-26,7 \%\right.$ ) (Tabela 2). Tal mistura de plantas $\mathrm{C}_{3}$ e $\mathrm{C}_{4}$ pode reforçar a interpretação do resultado de $-22,0 \%$ encontrado na camada superficial do solo localizado no campo do $\mathrm{km}$ 74 (Figura 4).

abela 3 - Lista das espécies ocorrentes no ecótono natural de transição floresta-campo no sul do estado do Amazonas. Formas de vida: A - arbóreo; Arb - arbustivo; Hb - herbáceo; L - liana; E - erva; Ep - epífitas. Ocorrência: F - floresta; B - borda; C - campo; - ausente.

\begin{tabular}{|c|c|c|c|}
\hline \multirow{2}{*}{$\begin{array}{l}\text { Família } \\
\text { Gênero e espécie }\end{array}$} & \multirow{2}{*}{$\begin{array}{l}\text { Formas } \\
\text { de vida }\end{array}$} & \multicolumn{2}{|c|}{ Ocorrência } \\
\hline & & $\mathrm{km} 74$ & $\mathrm{~km} 83$ \\
\hline \multicolumn{4}{|l|}{ Anacardiaceae } \\
\hline Tapirira guianensis Aubl. & A & $\mathrm{F}, \mathrm{B}, \mathrm{C}$ & - \\
\hline \multicolumn{4}{|l|}{ Annonaceae } \\
\hline Annona sp1 & A & $\mathrm{F}, \mathrm{B}, \mathrm{C}$ & $\mathrm{F}, \mathrm{B}$ \\
\hline Annona sp2 & A & $\mathrm{F}$ & - \\
\hline Annona sp 3 & A & $\mathrm{F}$ & - \\
\hline Annona sp 4 & A & B & B \\
\hline Annona sp 5 & A & $\mathrm{F}, \mathrm{B}$ & $\mathrm{F}$ \\
\hline Annona sp 6 & A & - & B \\
\hline Annona sp7 & A & - & B \\
\hline Guatteria sp & A & C & - \\
\hline Xylopia aromatica (Lam.) Mart. & A & B & $\mathrm{B}, \mathrm{C}$ \\
\hline \multicolumn{4}{|l|}{ Apocynaceae } \\
\hline Couma guianensis Aubl. & A & $\mathrm{B}$ & - \\
\hline $\begin{array}{l}\text { Geissospermum aff. urceolatum A.H. } \\
\text { Gentry }\end{array}$ & A & $\mathrm{F}, \mathrm{B}$ & $\mathrm{F}$ \\
\hline
\end{tabular}




\begin{tabular}{|c|c|c|c|}
\hline $\begin{array}{l}\text { Himatanthus sucuuba (Spruce ex Müll. } \\
\text { Arg.) Woodson }\end{array}$ & A & $\mathrm{F}, \mathrm{B}, \mathrm{C}$ & $B, C$ \\
\hline \multicolumn{4}{|l|}{ Araceae } \\
\hline Philodendron sp & Ep & $\mathrm{F}$ & $\mathrm{F}$ \\
\hline \multicolumn{4}{|l|}{ Araliaceae } \\
\hline $\begin{array}{l}\text { Schefflera morototoni (Aubl.)Maguire, } \\
\text { Steyerm. \& Frodin }\end{array}$ & A & $\mathrm{F}, \mathrm{C}$ & $\mathrm{B}$ \\
\hline \multicolumn{4}{|l|}{ Arecaceae } \\
\hline Allagoptera caudescens (Mart.) Kuntze & & $\mathrm{F}$ & $\mathrm{F}$ \\
\hline Astrocaryum acaule Mart. & A & $F, B$ & $\mathrm{~F}, \mathrm{~B}$ \\
\hline Desmoncus polyacanthos Mart. & & - & B \\
\hline Euterpe precatoria Mart. & Arb & $\mathrm{F}, \mathrm{B}$ & $\mathrm{F}, \mathrm{B}$ \\
\hline Geonoma multiflora Mart. & Arb & $\mathrm{F}$ & $\mathrm{F}$ \\
\hline Lepidocaryum tenue Mart. & & - & $\mathrm{F}$ \\
\hline Mauritia flexuosa L. f. & A & $\mathrm{F}$ & - \\
\hline Mauritiella armata (Mart.) Burret & A & $\mathrm{F}, \mathrm{B}$ & C \\
\hline Oenocarpus bacaba Mart. & A & $\mathrm{F}, \mathrm{B}$ & $\mathrm{F}, \mathrm{B}$ \\
\hline Oenocarpus bataua Mart. & A & $\mathrm{F}, \mathrm{B}$ & $\mathrm{F}$ \\
\hline Oenocarpus minor Mart. & A & $\mathrm{F}$ & $\mathrm{F}$ \\
\hline Orbignya speciosa (Mart.) Barb. Rodr. & A & $\mathrm{F}, \mathrm{B}$ & $\mathrm{F}, \mathrm{B}$ \\
\hline Socratea exorrhiza (Mart.) H. Wendl. & A & $\mathrm{F}$ & B \\
\hline \multicolumn{4}{|l|}{ Asteraceae } \\
\hline Eupatorium sp & $\mathrm{E}$ & C & C \\
\hline Piptocarpha sp & A & - & C \\
\hline Vernonia herbacea (Vell.) Rusby & $E$ & C & - \\
\hline \multicolumn{4}{|l|}{ Bignoniaceae } \\
\hline Jacaranda sp 1 & A & $\mathrm{F}$ & - \\
\hline Jacaranda sp 2 & A & $\mathrm{F}$ & $\mathrm{F}$ \\
\hline Pleonotoma jasminifolia (Kunth) Miers & $\mathrm{L}$ & - & $\mathrm{F}$ \\
\hline \multicolumn{4}{|l|}{ Bombacaceae } \\
\hline Eriotheca sp & A & - & C \\
\hline \multicolumn{4}{|l|}{ Bromeliaceae } \\
\hline Ananas ananassoides (Baker) L.B. Smith & $\mathrm{Hb}$ & B & - \\
\hline Bromelia spn & & - & $\mathrm{F}, \mathrm{B}$ \\
\hline Bromelia sp 2 & & - & $\mathrm{F}$ \\
\hline \multicolumn{4}{|l|}{ Burseraceae } \\
\hline Bursera sp & A & $\mathrm{F}$ & - \\
\hline Hemicrepidospermum sp & A & $\mathrm{F}$ & - \\
\hline Protium paniculatum Engl. & A & $\mathrm{F}, \mathrm{B}$ & $\mathrm{F}, \mathrm{B}$ \\
\hline Protium sp1 & A & $\mathrm{F}$ & - \\
\hline Protium sp2 & A & $\mathrm{F}$ & - \\
\hline \multicolumn{4}{|l|}{ Celastraceae } \\
\hline Goupia glabra Aubl. & A & $\mathrm{F}, \mathrm{B}, \mathrm{C}$ & $\mathrm{F}$ \\
\hline \multicolumn{4}{|l|}{ Chrysobalanaceae } \\
\hline Couepia sp & A & $B, C$ & - \\
\hline Licania sp1 & A & $\mathrm{B}, \mathrm{C}$ & $B, C$ \\
\hline Licania sp2 & A & - & B \\
\hline Licania sp3 & A & - & B \\
\hline Licania sp4 & A & - & $\mathrm{F}$ \\
\hline \multicolumn{4}{|l|}{ Clusiaceae } \\
\hline Caraipa savannarum Kubitzki & $A$ & $\mathrm{~F}, \mathrm{~B}, \mathrm{C}$ & $B, C$ \\
\hline Vismia cayennensis (Jacq.) Pers. & $A$ & B & - \\
\hline
\end{tabular}

\begin{tabular}{|c|c|c|c|}
\hline Vismia guianensis (Aubl.) Pers. & A & $\mathrm{F}, \mathrm{B}, \mathrm{C}$ & B, C \\
\hline Vismia latifolia (Aubl.) Choisy & A & C & B \\
\hline Vismia sp & A & C & - \\
\hline \multicolumn{4}{|l|}{ Cyperaceae } \\
\hline Bulbostylis sp & $\mathrm{E}$ & C & C \\
\hline Cyperus sp & $\mathrm{E}$ & C & C \\
\hline Fimbristylis sp & $\mathrm{E}$ & C & C \\
\hline Kyllinga sp & $\mathrm{E}$ & C & C \\
\hline Rhynchospora sp & $\mathrm{E}$ & C & C \\
\hline Scleria aff reflexa Kunth & $\mathrm{Hb}$ & $B, C$ & $F, B$ \\
\hline Scleria sp1 & $\mathrm{Hb}$ & - & $\mathrm{F}, \mathrm{C}$ \\
\hline Scleria sp2 & $\mathrm{Hb}$ & - & $\mathrm{F}$ \\
\hline \multicolumn{4}{|l|}{ Dilleniaceae } \\
\hline Curatella americana L. & A & C & C \\
\hline Davilla rugosa Poir & $\mathrm{L}$ & B & $\mathrm{F}, \mathrm{B}$ \\
\hline Davilla sp & $\mathrm{L}$ & - & B \\
\hline \multicolumn{4}{|l|}{ Euphorbiaceae } \\
\hline Euphorbia sp & L & $\mathrm{B}, \mathrm{C}$ & - \\
\hline Hevea brasiliensis Müll. Arg. & A & $\mathrm{F}, \mathrm{B}$ & B \\
\hline Hevea sp & A & - & B \\
\hline Jatropha phyllacantha Muell. Arg. & A & C & - \\
\hline Mabea caudata Pax \& K. Hoffm & A & $\mathrm{B}, \mathrm{C}$ & B \\
\hline Mabea subsessilis Pax \& K. Hoffm & A & $\mathrm{F}, \mathrm{B}, \mathrm{C}$ & F, B, C \\
\hline \multicolumn{4}{|l|}{ Fabaceae } \\
\hline Alexa grandiflora Ducke & A & - & $\mathrm{F}, \mathrm{B}$ \\
\hline Andira sp & A & $B, C$ & C \\
\hline Bauhinia guianensis Aubl. & A & $\mathrm{F}, \mathrm{B}$ & $\mathrm{F}$ \\
\hline Bauhinia sp & A & C & $\mathrm{F}$ \\
\hline Bowdichia virgilioides Kunth & & C & C \\
\hline Dinizia excelsa Ducke & A & - & $F, B$ \\
\hline Dioclea cf huberi Ducke & $\mathrm{L}$ & C & C \\
\hline Dipteryx odorata (Aubl.) Willd & A & $\mathrm{F}, \mathrm{B}$ & - \\
\hline Hymenaea sp & A & $\mathrm{F}$ & - \\
\hline Inga sp & A & $\mathrm{F}, \mathrm{B}, \mathrm{C}$ & $\mathrm{F}$ \\
\hline Mimosa sp & A & $\mathrm{F}$ & - \\
\hline Ormosia sp & A & $\mathrm{F}$ & - \\
\hline Parkia cf nitida Miq. & A & - & $\mathrm{F}, \mathrm{B}$ \\
\hline Parkia sp & A & - & $\mathrm{F}$ \\
\hline Sclerolobium paniculatum Vogel & A & $\mathrm{B}, \mathrm{C}$ & $B, C$ \\
\hline Tachigali myrmecophilla (Ducke) Ducke & A & $\mathrm{F}, \mathrm{B}$ & $\mathrm{F}$ \\
\hline \multicolumn{4}{|l|}{ Flacourtiaceae } \\
\hline Casearia grandiflora Cambess. & A & $B, C$ & B \\
\hline Casearia sp & A & B & B \\
\hline \multicolumn{4}{|l|}{ Heliconiaceae } \\
\hline Heliconia psittacorum L.f. & $\mathrm{Hb}$ & $\mathrm{F}$ & $\mathrm{F}, \mathrm{B}, \mathrm{C}$ \\
\hline Heliconia sp & $\mathrm{Hb}$ & - & B \\
\hline \multicolumn{4}{|l|}{ Lauraceae } \\
\hline Aniba sp1 & A & $F, B$ & $\mathrm{~F}, \mathrm{~B}$ \\
\hline Aniba sp2 & A & $F, B$ & - \\
\hline Nectandra cuspidata Nees \& Mart. & A & $\mathrm{F}$ & $\mathrm{F}$ \\
\hline Nectandra lanceolata Nees & A & $\mathrm{F}$ & - \\
\hline Ocotea sp1 & A & F, B & $\mathrm{F}$ \\
\hline
\end{tabular}




\begin{tabular}{|c|c|c|c|}
\hline Eschweilera sp & A & $\mathrm{F}, \mathrm{C}$ & - \\
\hline \multicolumn{4}{|l|}{ Linaceae } \\
\hline Ochthocosmus cf barrae Hallier f. & A & C & $\mathrm{B}, \mathrm{C}$ \\
\hline \multicolumn{4}{|l|}{ Lythraceae } \\
\hline Cuphea sp & $\mathrm{Hb}$ & C & - \\
\hline Physocalymma scaberrimum Pohl & A & $B, C$ & C \\
\hline \multicolumn{4}{|l|}{ Malpighiaceae } \\
\hline Banisteriopsis sp & A & C & - \\
\hline Byrsonima sp1 & A & C & $B, C$ \\
\hline Byrsonima sp2 & $A$ & C & - \\
\hline Byrsonima coccolobaefolia Kunth & Arb & - & C \\
\hline Byrsonima cf verbascifolia (L.) DC. & A & B & - \\
\hline \multicolumn{4}{|l|}{ Malvaceae } \\
\hline Hibiscus furcellatus Desr. & A & $\mathrm{B}, \mathrm{C}$ & - \\
\hline \multicolumn{4}{|l|}{ Marantacae } \\
\hline Ischnosiphon sp & $\mathrm{Hb}$ & - & $\mathrm{F}, \mathrm{B}$ \\
\hline Monotagma sp & $\mathrm{Hb}$ & $\mathrm{F}, \mathrm{B}$ & B \\
\hline \multicolumn{4}{|l|}{ Melastomataceae } \\
\hline Bellucia grossularioides (L.) Triana & $A$ & $F, B, C$ & $\mathrm{~F}, \mathrm{~B}$ \\
\hline Miconia tiliifolia Naudin & A & B & $\mathrm{F}$ \\
\hline Miconia sp & $A$ & C & $F, B, C$ \\
\hline Miconia sp2 & $A$ & - & F, B \\
\hline Miconia sp3 & A & C & $\mathrm{F}, \mathrm{B}$ \\
\hline Miconia sp4 & A & - & B \\
\hline Tibouchina aspera Aubl. & Arb & $F, B$ & $\mathrm{~F}$ \\
\hline Tibouchina sp & A & C & - \\
\hline Tococa guianensis Aubl. & & - & $\mathrm{F}$ \\
\hline \multicolumn{4}{|l|}{ Monimiaceae } \\
\hline Siparuna guianensis Aubl. & Arb & $\mathrm{F}, \mathrm{B}, \mathrm{C}$ & $\mathrm{F}, \mathrm{B}$ \\
\hline Siparuna sp & A & C & - \\
\hline \multicolumn{4}{|l|}{ Moraceae } \\
\hline Naucleopsis caloneura (Huber) Ducke & A & $\mathrm{F}, \mathrm{B}$ & - \\
\hline \multicolumn{4}{|l|}{ Myristicaceae } \\
\hline Iryanthera sp & A & F, C & $\mathrm{F}$ \\
\hline Virola sebifera Aubl. & A & $\mathrm{F}, \mathrm{C}$ & B \\
\hline Virola surinamensis (Rol ex Rottb.) Warb. & A & $\mathrm{F}, \mathrm{B}$ & - \\
\hline Virola sp & A & C & C \\
\hline Virola sp2 & A & C & - \\
\hline \multicolumn{4}{|l|}{ Myrtaceae } \\
\hline Eugenia sp1 & A & $\mathrm{F}, \mathrm{B}, \mathrm{C}$ & F, B, C \\
\hline Eugenia sp2 & $A$ & $\mathrm{~B}, \mathrm{C}$ & $\mathrm{B}, \mathrm{C}$ \\
\hline Eugenia sp3 & $A$ & - & F, B \\
\hline Myrcia sp & A & $\mathrm{B}, \mathrm{C}$ & - \\
\hline \multicolumn{4}{|l|}{ Olacaceae } \\
\hline Minquartia guianensis Aubl. & $A$ & - & B \\
\hline \multicolumn{4}{|l|}{ Piperaceae } \\
\hline Piper sp 1 & Arb & $\mathrm{F}$ & F, B \\
\hline Piper sp 2 & Arb & $\mathrm{F}$ & $\mathrm{F}$ \\
\hline Piper sp 3 & Arb & $\mathrm{F}$ & - \\
\hline Piper sp 4 & Arb & $\mathrm{F}$ & - \\
\hline Piper sp 5 & Arb & $\mathrm{F}$ & - \\
\hline \multicolumn{4}{|l|}{ Poaceae } \\
\hline Andropogon bicornis L. & $E$ & C & - \\
\hline
\end{tabular}

\begin{tabular}{|c|c|c|c|}
\hline Andropogon lanatus $\mathrm{R} . \mathrm{Br}$. & $\mathrm{E}$ & C & C \\
\hline Andropogon leucostachyus Kunth & E & $\mathrm{B}, \mathrm{C}$ & C \\
\hline Andropogon sp & $\mathrm{E}$ & - & C \\
\hline Aristida capillacea Lam. & $E$ & C & - \\
\hline Axonopus aureus P. Beauv & $\mathrm{E}$ & C & C \\
\hline Lasiacis cf ligulata Hitch \& Chase & $\mathrm{E}$ & $\mathrm{F}, \mathrm{B}$ & $\mathrm{F}, \mathrm{B}$ \\
\hline Panicum parvifolium Lam. & $\mathrm{E}$ & C & C \\
\hline Paspalum sp1 & $\mathrm{E}$ & C & C \\
\hline Paspalum sp2 & E & C & C \\
\hline \multicolumn{4}{|l|}{ Rubiaceae } \\
\hline Alibertia edulis (Rich.) A. Rich. ex DC. & A & $\mathrm{B}, \mathrm{C}$ & $B, C$ \\
\hline Alibertia sp & A & - & $\mathrm{F}, \mathrm{B}$ \\
\hline Chomelia sp & & - & $\mathrm{F}$ \\
\hline Palicourea sp & & C & B \\
\hline Psychotria sp & & B & $\mathrm{F}, \mathrm{B}$ \\
\hline \multicolumn{4}{|l|}{ Sapotaceae } \\
\hline Pouteria guianensis Aubl. & A & $\mathrm{B}, \mathrm{C}$ & - \\
\hline Pouteria sp1 & A & $\mathrm{F}, \mathrm{B}, \mathrm{C}$ & $\mathrm{F}, \mathrm{B}, \mathrm{C}$ \\
\hline Pouteria sp2 & A & - & $\mathrm{F}, \mathrm{B}$ \\
\hline \multicolumn{4}{|l|}{ Selaginellaceae } \\
\hline Selaginella fragilis A. Braun & $\mathrm{Hb}$ & B & $\mathrm{B}$ \\
\hline \multicolumn{4}{|l|}{ Smilacaceae } \\
\hline Smilax sp & & - & $\mathrm{B}$ \\
\hline \multicolumn{4}{|l|}{ Solanaceae } \\
\hline Solanum sp & & C & - \\
\hline \multicolumn{4}{|l|}{ Strelitziaceae } \\
\hline Phenakospermum guianensis Aubl. & A & $\mathrm{F}, \mathrm{B}$ & $\mathrm{F}, \mathrm{B}$ \\
\hline \multicolumn{4}{|l|}{ Ulmaceae } \\
\hline Trema micrantha (L.) Blume & A & B, C & $\mathrm{F}, \mathrm{B}$ \\
\hline \multicolumn{4}{|l|}{ Vochysiaceae } \\
\hline Qualea grandiflora Mart. & $A$ & C & C \\
\hline Qualea parviflora Mart. & A & C & C \\
\hline Qualea sp & $A$ & C & C \\
\hline Salvertia convallariodora A. St. -Hil. & A & C & - \\
\hline Vochysia bracteata & A & - & C \\
\hline Vochysia haenkeana Mart. & A & C & $\mathrm{B}, \mathrm{C}$ \\
\hline Vochysia sp & A & $\mathrm{B}, \mathrm{C}$ & - \\
\hline № de Famílias & & 40 & 38 \\
\hline № de Gêneros & & 94 & 82 \\
\hline $\mathrm{N}^{0}$ de Espécies & & 131 & 120 \\
\hline
\end{tabular}

No km 83 registrou-se a ocorrência de 120 espécies e 82 gêneros distribuídos em 38 famílias (Tabela 3). As famílias predominantes em números de espécies foram: Fabaceae (12 espécies), Arecaceae (12), Poaceae (8), Melastomataceae (8), Cyperaceae (8), Annonaceae (6) e Vochysiaceae (5). A forma de vida caracterizou-se pela presença de 77 espécies arbóreas, 23 espécies de ervas, 12 arbustivas, 4 lianas e 3 epífitas.

$\mathrm{Na}$ floresta as espécies predominantes no estrato arbóreo foram: Orbignya speciosa (24 indivíduos), Goupia glabra (13) e Astrocaryum acaule (5). A densidade arbórea foi estimada em $430 \mathrm{ind} / \mathrm{ha}$ e a área basal em $30,7 \mathrm{~m}^{2} / \mathrm{ha}$. Os valores médios 
obtidos para os parâmetros altura da copa, CAP e distância entre as árvores foram de $16,33 \pm 4,18 \mathrm{~m}, 89 \pm 45 \mathrm{~cm}$ e 4,83 $\pm 2,13 \mathrm{~m}$, respectivamente.

$\mathrm{Na}$ borda as espécies com maior número de indivíduos foram: Ochthocosmus cfbarrae (21), Himatanthus sucuuba (6), Mabea subsessilis (5) e Vochysia haenkeana (4). A densidade arbórea foi estimada em 1080 ind/ha e a área basal em 13,5 $\mathrm{m}^{2} / \mathrm{ha}$. A altura média das árvores foi de $12,34 \pm 3,6 \mathrm{~m}$, CAP médio de $63 \pm 17 \mathrm{~cm}$ e distância média de 3,05 $\pm 1,61 \mathrm{~m}$.

No campo as espécies arbóreas predominantes foram: Caraipa savannarum (13), Pouteria sp1 (10), Ochthocosmus cf barrae (10) e Mabea subsessilis (9). No estrato herbáceo predominaram as gramíneas do gênero Andropogon (46\%) e Paspalum (21,5\%).

\section{PARÂMETROS FITOSSOCIOLÓGICOS}

Nas Tabelas 4, 5 e 6 observam-se os valores relativos de densidade (DR), freqüência (FR) e dominância (DoR) e o índice de valor de importância (IVI) das espécies da floresta, da borda e dos aglomerados arbóreos do campo, respectivamente, no $\mathrm{km} 74$. As espécies de maior IVI na floresta foram Mabea subsessilis (25,1), Hymenaea sp (16,8), Orbignya speciosa $(16,7)$, Euterpe precatoria (16,6), Vismia guianensis (15,5), Oenocarpus bacaba (10,4), Caraipa savannarum $(9,1)$ e Protium sp $(6,8)$ (Tabela 4). Essas espécies representaram $40 \%$ do valor total do IVI.

$\mathrm{Na}$ borda (Tabela 5) as espécies com maiores IVI foram Himatanthus sucuuba (30,1), Sclerolobium paniculatum $(27,2)$, Licania sp (17,7), Inga sp (15,2), Mabea caudata (14,8), Andira sp $(12,3)$, Pouteria sp1 $(9,5)$, Xylopia aromatica $(8,8)$, Tapirira guianensis $(8,8)$ e Bellucia grossularioides $(8,2)$. Essas espécies representaram $51 \%$ do valor total do IVI. As espécies com maiores IVI foram as heliófilas, características de ambientes com maior luminosidade e, conseqüentemente, as espécies que apresentaram o maior número de indivíduos amostrados na borda. Das espécies de ampla distribuição no Brasil Central encontradas nas bordas dos Campos de Humaitá, a Caraipa savannarum (Clusiaceae) e a Physocalymma scaberrimum (Lythraceae) não ocorrem na Amazônia Central e Norte (Ribeiro et al., 1999). Portanto, apresentam características florísticas dos encraves de savanas ao sul da Amazônia (Gottsberger \& Morawetz, 1986; Kubitzki, 1985).

Nos "aglomerados arbóreos" localizados no campo (Tabela 6), as espécies que apresentaram maiores IVI foram Himatanthus sucuuba (40,9); Sclerolobium paniculatum $(34,9)$; Caraipa savannarum (24,1); Ochthocosmus of barrae $(19,6)$; Byrsonima sp1 (16,6); Physocalymma scaberrimum $(9,86)$; Bowdichia virgilioides $(9,5)$ e Vochysia haenkeana $(9,1)$. Juntas, essas espécies somaram $55 \%$ do valor total do IVI. As espécies Himatanthus sucuuba e Sclerolobium paniculatum foram mais abundantes na borda do ecótono, quando comparado com a floresta, portanto os altos índices de IVI e dos parâmetros relativos de densidade, freqüência e dominância encontrados para essas espécies no campo podem ser indicativo de que elas estariam se expandindo para o mesmo. Tais espécies foram encontradas em "aglomerados" arbóreos existentes no campo. Neste local, distante aproximadamente $50 \mathrm{~m}$ da borda, indivíduos jovens dessas espécies predominavam e começavam a se desenvolver no campo. Ressalta-se que esses campos eram predominados por gramíneas e as únicas espécies arbóreas

Tabela 4 - Parâmetros fitossociológicos, em ordem decrescente pelo índice de valor de importância por espécie (IVI) da floresta no km 74 .

\begin{tabular}{|c|c|c|c|c|}
\hline Espécie & $\mathrm{DR}(\%)$ & FR (\%) & DoR (\%) & IVI (\%) \\
\hline 1. Mabea subsessilis & 4,33 & 3,83 & 16,92 & 25,07 \\
\hline 2. Hymenaea sp & 2,4 & 2,73 & 11,62 & 16,75 \\
\hline 3. Orbignya speciosa & 5,29 & 4,37 & 7,07 & 16,73 \\
\hline 4. Euterpe precatoria & 8,65 & 4,92 & 3,03 & 16,6 \\
\hline 5. Vismia guianensis & 8,17 & 5,46 & 1,89 & 15,53 \\
\hline 6. Oenocarpus bacaba & 4,81 & 4,92 & 0,63 & 10,36 \\
\hline 7. Caraipa savannarum & 2,4 & 2,73 & 3,91 & 9,05 \\
\hline 8. Protium sp & 2,88 & 3,28 & 0,63 & 6,79 \\
\hline 9. Protium paniculatum & 1,92 & 2,19 & 0,88 & 4,99 \\
\hline 10. Virola sebifera & 1,92 & 2,19 & 0,76 & 4,87 \\
\hline 11. Mauritiella armata & 2,4 & 1,64 & 0,51 & 4,55 \\
\hline 12. Ocotea sp1 & 1,44 & 1,64 & 0,88 & 3,97 \\
\hline 13. Naucleopsis caloneura & 1,44 & 1,64 & 0,63 & 3,71 \\
\hline 14. Himatanthus sucuuba & 0,96 & 1,09 & 1,64 & 3,7 \\
\hline 15. Hemicrepidospermum sp & 1,44 & 1,64 & 0,51 & 3,59 \\
\hline 16. Mauritia flexuosa & 0,96 & 1,09 & 1,52 & 3,57 \\
\hline 17. Anonna sp 2 & 1,44 & 1,64 & 0,38 & 3,46 \\
\hline 18. Anonna sp 5 & 1,44 & 1,64 & 0,38 & 3,46 \\
\hline 19. Phenakospermum guianensis & 1,44 & 1,64 & 0,25 & 3,33 \\
\hline $\begin{array}{l}\text { 20. Geissospermum aff. } \\
\text { urceolatum }\end{array}$ & 0,96 & 1,09 & 1,01 & 3,06 \\
\hline 21. Goupia glabra & 0,96 & 1,09 & 0,38 & 2,43 \\
\hline 22. Oenocarpus minor & 0,96 & 1,09 & 0,13 & 2,18 \\
\hline 23. Ocotea sp2 & 0,96 & 1,09 & 0,13 & 2,18 \\
\hline 24. Eschweilera sp & 0,48 & 0,55 & 1,14 & 2,16 \\
\hline 25. Tapirira guianensis & 0,48 & 0,55 & 0,88 & 1,91 \\
\hline 26. Socratea exorrhiza & 0,96 & 0,55 & 0,38 & 1,89 \\
\hline 27. Oenocarpus bataua & 0,48 & 0,55 & ,038 & 1,41 \\
\hline 28. Iryanthera sp & 0,48 & 0,55 & 0,25 & 1,28 \\
\hline 29. Anonna sp 1 & 0,48 & 0,55 & 0,13 & 1,15 \\
\hline 30. Bursera sp & 0,48 & 0,55 & 0,13 & 1,15 \\
\hline 31. Siparuna guianensis & 0,48 & 0,55 & 0,13 & 1,15 \\
\hline 32. Anonna sp 3 & 0,48 & 0,55 & 0,13 & 1,15 \\
\hline 33. Protium almecega & 0,48 & 0,55 & 0,13 & 1,15 \\
\hline 34. Astrocaryum acaule & 0,48 & 0,55 & 0,13 & 1,15 \\
\hline 35. Ormosia sp & 0,48 & 0,55 & 0,13 & 1,15 \\
\hline 36. Nectandra lanceolata & 0,48 & 0,55 & 0 & 1,03 \\
\hline \multirow[t]{2}{*}{ 37. Outras espécies } & 33,65 & 38,25 & 40,53 & 112,44 \\
\hline & 100 & 100 & 100 & 300 \\
\hline
\end{tabular}


Tabela 5 - Parâmetros fitossociológicos, em ordem decrescente pelo índice de valor de importância por espécie (IVI) da borda no km 74.

\begin{tabular}{lllll}
\hline Espécie & DR (\%) & FR (\%) & DoR (\%) & IVI (\%) \\
\hline 1. Himatanthus sucuuba & 8,75 & 7,94 & 13,38 & 30,06 \\
\hline 2. Sclerolobium paniculatum & 11,25 & 6,35 & 9,55 & 27,15 \\
\hline 3. Licania sp & 5 & 6,35 & 6,37 & 17,72 \\
\hline 4. Inga sp & 3,75 & 3,17 & 8,28 & 15,2 \\
\hline 5. Mabea caudata & 6,25 & 4,78 & 3,82 & 14,83 \\
\hline 6. Andira sp & 5 & 4,76 & 2,55 & 12,31 \\
\hline 7. Pouteria sp 1 & 3,75 & 3,17 & 2,55 & 9,47 \\
8. Xylopia aromática & 3,75 & 3,17 & 1,91 & 8,84 \\
9. Tapirira guianensis & 3,75 & 3,17 & 1,91 & 8,84 \\
\hline 10. Bellucia grossularioides & 3,75 & 3,17 & 1,27 & 8,2 \\
\hline 11. Aniba sp & 2,5 & 3,17 & 1,27 & 6,95 \\
12. Naucleopsis caloneura & 2,5 & 3,17 & 1,27 & 6,95 \\
\hline 13. Physocaymma scaberrimum & 1,25 & 1,59 & 3,82 & 6,66 \\
\hline 14. Aniba sp2 & 2,5 & 1,59 & 2,55 & 6,64 \\
\hline 15. Annona sp1 & 2,5 & 3,17 & 0,64 & 6,31 \\
\hline 16. Caraipa savannarum & 2,5 & 3,17 & 0,64 & 6,31 \\
\hline 17. Casearia grandiflora & 2,5 & 3,17 & 0,64 & 6,31 \\
\hline 18. Byrsonima cf verbascifolia & 1,25 & 1,59 & 2,55 & 5,39 \\
\hline 19. Geissospermum aff urceolatum & 1,25 & 1,59 & 2,55 & 5,39 \\
\hline 20. Alibertia edulis & 2,5 & 1,59 & 1,27 & 5,36 \\
\hline 21. Myrcia sp & 1,25 & 1,59 & 1,27 & 4,11 \\
\hline 22. Dipteryx odorata & 1,25 & 1,59 & 1,27 & 4,11 \\
\hline 23. Protium paniculatum & 1,25 & 1,59 & 0,64 & 3,47 \\
\hline 24. Phenakospermum guianensis & 1,25 & 1,59 & 0,64 & 3,47 \\
\hline 25. Annona sp 5 & 1,25 & 1,59 & 0,64 & 3,47 \\
\hline 26. Vismia cayennensis & 1,25 & 1,59 & 0,64 & 3,47 \\
\hline 27. Annona sp4 & 1,25 & 1,59 & 0 & 2,84 \\
\hline 28. Ocotea sp 2 & 1,25 & 1,59 & 0 & 2,84 \\
\hline 29. Mauritiella armata & 1,25 & 1,59 & 0 & 2,84 \\
\hline 30. Siparuna guianensis & 1,25 & 1,59 & 0 & 2,84 \\
31. Outras espécies & 11,25 & 14,29 & 26,11 & 51,65 \\
\hline & 100 & 100 & 100 & 300 \\
\hline & & & & \\
\hline
\end{tabular}

encontradas estavam nesses "aglomerados". Morelato \& Rosa (1991) observaram que a espécie Sclerolobium paniculatum foi mais freqüente em beiras de mata na região de Serra dos Carajás (PA), em estudo de caracterização de alguns tipos de vegetação na região.

Nas Tabela 7 e 8 observam-se os valores relativos de densidade (DR), freqüência (FR) e dominância (DoR) e o índice de valor de importância (IVI) das espécies da floresta e da borda, respectivamente, no $\mathrm{km} 83$.

$\mathrm{Na}$ floresta as espécies com maiores IVI foram Orbignya speciosa (80,6), Goupia glabra (62,1), Astrocaryum acaule $(16,3)$, Licania sp3 (13,2), Geissospermum aff urceolatum $(10,4)$, Protium paniculatum (10,2), Parkia sp (10,1), Iryanthera sp $(7,6)$ e Aniba sp1 $(7,1)$. Essas espécies representaram $73 \%$ do valor total do IVI (Tabela 7).
$\mathrm{Na}$ borda as espécies com maiores IVI foram Ochthocosmus cf barrae (59,3), Himatanthus sucuuba (25,3), Mabea subsessilis (18,6), Vochysia haenkeana (14,7), Aniba sp1 $(14,0)$, Byrsonima sp1 (14,0), Licania sp1 (11,1), Licania sp2 (10,0), Caraipa savannarum $(10,0)$ e Mabea caudata $(7,9)$. Essas espécies representam $62 \%$ do valor total do IVI. A espécie Ochthocosmus cf barrae apresentou maior dominância relativa com 18,4\% (Tabela 8).

As espécies com maior IVI, assim como ocorreu no ecótono 74 foram, na grande maioria, espécies heliófilas, e as que apresentaram o maior número de indivíduos amostrados.

Tabela 6 - Parâmetros fitossociológicos, em ordem decrescente pelo índice de valor de importância por espécie (IVI) dos "aglomerados arbóreos" no $\mathrm{km} 74$.

\begin{tabular}{lllll}
\hline Espécie & DR (\%) & FR (\%) & DoR (\%) & IVI (\%) \\
\hline 1. Himatanthus sucuuba & 13,81 & 8,33 & 18,76 & 40,9 \\
\hline 2. Sclerolobium paniculatum & 11,57 & 8,33 & 15,04 & 34,94 \\
\hline 3. Caraipa savannarum & 9,33 & 6,41 & 8,32 & 24,06 \\
\hline 4. Ochthocosmus cf barrae & 6,34 & 5,77 & 7,43 & 19,55 \\
\hline 5. Byrsonima sp1 & 5,97 & 5,13 & 5,49 & 16,59 \\
\hline 6. Physocalimma scaberrimum & 3,36 & 3,85 & 2,65 & 9,86 \\
\hline 7. Bowdichia virgilioides & 2,61 & 3,21 & 3,72 & 9,53 \\
\hline 8. Vochysia haenkeana & 3,36 & 2,56 & 3,19 & 9,11 \\
\hline 9. Andira sp & 3,36 & 2,56 & 3,01 & 8,93 \\
\hline 10. Salvertia convallariodora & 2,24 & 3,21 & 1,95 & 7,39 \\
\hline 11. Virola sp & 2,61 & 2,56 & 2,12 & 7,3 \\
\hline 12. Alibertia edulis & 2,24 & 2,56 & 2,48 & 7,28 \\
\hline 13. Casearia grandiflora & 2,61 & 1,92 & 2,12 & 6,66 \\
\hline 14. Schefflera morototoni & 1,87 & 1,92 & 2,83 & 6,62 \\
\hline 15. Pouteria sp & 1,87 & 3,21 & 1,42 & 6,49 \\
\hline 16. Eugenia sp & 1,87 & 1,92 & 1,06 & 4,85 \\
\hline 17. Curatella americana & 1,49 & 2,56 & 0,53 & 4,59 \\
\hline 18. Mabea caudata & 1,49 & 1,28 & 1,24 & 4,01 \\
\hline 19. Vismia guianensis & 1,12 & 1,92 & 0,88 & 3,93 \\
\hline 20. Goupia glabra & 1,12 & 1,92 & 0,71 & 3,75 \\
\hline 21. Xylopia aromatica & 1,12 & 1,28 & 1,24 & 3,64 \\
\hline 22. Qualea sp & 0,75 & 1,28 & 1,06 & 3,09 \\
\hline 23. Siparuna guianensis & 1,12 & 1,28 & 0,53 & 2,93 \\
\hline 24. Vismia latifolia & 0,75 & 1,28 & 0,71 & 2,74 \\
\hline 25. Banisteriopsis sp & 0,75 & 1,28 & 0,53 & 2,56 \\
\hline 26. Miconia sp3 & 0,75 & 1,28 & 0,53 & 2,56 \\
\hline 27. Qualea parviflora & 0,75 & 0,64 & 1,06 & 2,45 \\
\hline 28. Hibiscus sp & 0,37 & 0,64 & 1,42 & 2,43 \\
\hline 29. Guatteria sp & 0,75 & 1,28 & 0,35 & 2,38 \\
30. Bellucia sp & 0,75 & 1,28 & 0,35 & 2,38 \\
\hline 31. Trema micrantha & 0,75 & 0,64 & 0,53 & 1,92 \\
32. Couepia sp & 0,75 & 0,64 & 0,35 & 1,74 \\
33. Eugenia sp2 & 0,75 & 0,64 & 0,35 & 1,74 \\
\hline 34. Annona sp1 & 0,37 & 0,64 & 0,53 & 1,55 \\
\hline 35. Tibouchina sp & 0,37 & 0,06 & 0,53 & 1,55 \\
36. Vismia sp & 0,37 & 0,64 & 0,35 & 1,37 \\
\hline
\end{tabular}




\begin{tabular}{lllll}
\hline 37. Byrsonima sp2 & 0,37 & 0,64 & 0,35 & 1,37 \\
38. Miconia sp & 0,37 & 0,64 & 0,35 & 1,37 \\
39. Virola sp2 & 0,37 & 0,64 & 0,35 & 1,37 \\
40. Vochysia sp & 0,37 & 0,64 & 0,35 & 1,37 \\
\hline 41. Piptocarpha sp & 0,37 & 0,64 & 0,18 & 1,19 \\
42. Vernonia sp & 0,37 & 0,64 & 0,18 & 1,19 \\
\hline 43. Euphorbia sp & 0,37 & 0,64 & 0,18 & 1,19 \\
44. Bauhinia sp & 0,37 & 0,64 & 0,18 & 1,19 \\
\hline 45. Iryanthera sp & 0,37 & 0,64 & 0,18 & 1,19 \\
46. Palicourea sp & 0,37 & 0,64 & 0,18 & 1,19 \\
\hline 47. Pouteria sp2 & 0,37 & 0,64 & 0,18 & 1,19 \\
48. Qualea grandiflora & 0,37 & 0,64 & 0,18 & 1,19 \\
\hline 49. Myrcia sp & 0,37 & 0,64 & 0 & 1,01 \\
50. Siparuna sp & 0,37 & 0,64 & 0 & 1,01 \\
51. Solanum $\mathrm{sp}$ & 0,37 & 0,64 & 0 & 1,01 \\
\hline 52. Outras espécies & 2,96 & 3,85 & 2,12 & 8,93 \\
\hline & 100 & 100 & 100 & 300 \\
\hline
\end{tabular}

Tabela 7 - Parâmetros fitossociológicos, em ordem decrescente pelo índice de valor de importância por espécie (IVI) da floresta no km 83.

\begin{tabular}{lllll}
\hline Espécie & DR (\%) & FR (\%) & DoR (\%) & IVI \\
\hline 1. Orbignya speciosa & 30,77 & 17,86 & 31,93 & 80,56 \\
2. Goupia glabra & 16,67 & 12,5 & 32,92 & 62,09 \\
3. Astrocaryum acaule & 6,41 & 7,14 & 2,72 & 16,28 \\
4. Licania sp3 & 3,85 & 5,36 & 3,96 & 13,16 \\
\hline 5. Geissospermum aff urceolatum & 3,85 & 5,36 & 1,24 & 10,44 \\
6. Protium paniculatum & 3,85 & 5,36 & 0,99 & 10,19 \\
7. Parkia sp & 2,56 & 3,57 & 3,96 & 10,1 \\
8. Iryanthera sp & 2,56 & 3,57 & 1,49 & 7,62 \\
\hline 9. Aniba sp1 & 2,56 & 3,57 & 0,99 & 7,13 \\
10. Oenocarpus minor & 2,56 & 1,79 & 0,25 & 4,6 \\
\hline 11. Parkia cf nitida & 1,28 & 1,79 & 0,5 & 3,56 \\
12. Ocotea sp1 & 1,28 & 1,79 & 0,25 & 3,32 \\
\hline 13. Alexa grandiflora & 1,28 & 1,79 & 0,25 & 3,32 \\
14. Oenocarpus bacaba & 1,28 & 1,79 & 0,25 & 3,32 \\
\hline 15. Euterpe precatoria & 1,28 & 1,79 & 0,25 & 3,32 \\
\hline 16. Tachigali myrmecophila & 1,28 & 1,79 & 0 & 3,07 \\
\hline 17. Siparuna guianensis & 1,28 & 1,79 & 0, & 3,07 \\
\hline 18. Outras espécies & 15,38 & 21,43 & 18,07 & 54,88 \\
\hline & 100 & 100 & 100 & 300 \\
\hline
\end{tabular}

O ecótono 83 encontrava-se menos preservado que o 74 , onde pode-se observar muitas árvores cortadas, talvez por esse motivo neste ecótono não se destacou uma espécie que estaria indicando a atual expansão da floresta sobre o campo.

\section{CONCLUSÕES}

As datações ${ }^{14} \mathrm{C}$ da MOS dos perfis $\mathrm{HO}$ e THDF foram contemporâneas, indicando que não houve diferença significativa no período de incorporação da matéria orgânica
Tabela 8 - Parâmetros fitossociológicos, em ordem decrescente pelo índice de valor de importância por espécie (IVI) da borda no km 83.

\begin{tabular}{lllll}
\hline Espécie & DR (\%) & FR (\%) & DoR (\%) & IVI (\%) \\
\hline 1. Ochthocosmus cf barrae & 26,58 & 14,29 & 18,38 & 59,25 \\
2. Himatanthus sucuuba & 7,59 & 7,94 & 9,73 & 25,26 \\
3. Mabea subsessilis & 6,33 & 6,35 & 5,95 & 18,62 \\
4. Vochysia haenkeana & 5,06 & 4,76 & 4,86 & 14,69 \\
5. Aniba sp1 & 3,8 & 4,76 & 5,41 & 13,96 \\
6. Byrsonima sp1 & 3,8 & 4,76 & 5,41 & 13,96 \\
7. Licania sp1 & 2,53 & 3,17 & 5,41 & 11,11 \\
8. Licania sp2 & 2,53 & 3,17 & 4,32 & 10,03 \\
9. Caraipa savannarum & 2,53 & 3,17 & 4,32 & 10,03 \\
10. Mabea caudata & 2,53 & 1,59 & 3,78 & 7,9 \\
\hline 11. Orbignya speciosa & 1,27 & 1,59 & 4,86 & 7,72 \\
12. Xylopia aromatica & 2,53 & 3,17 & 1,08 & 6,79 \\
\hline 13. Sclerolobium paniculatum & 1,27 & 1,59 & 3,78 & 6,64 \\
14. Phenakospermum guianensis & 2,53 & 3,17 & 0,54 & 6,25 \\
15. Vismia guianensis & 1,27 & 1,59 & 2,7 & 5,56 \\
16. Licania sp3 & 1,27 & 1,59 & 2,16 & 5,02 \\
\hline 17. Dinizia excelsa & 1,27 & 1,59 & 2,16 & 5,02 \\
\hline 18. Schefflera morototoni & 1,27 & 1,59 & 1,08 & 3,93 \\
19. Alexa grandiflora & 1,27 & 1,59 & 0,54 & 3,39 \\
20. Casearia grandiflora & 1,27 & 1,59 & 0,54 & 3,39 \\
\hline 21. Minquartia guianensis & 1,27 & 1,59 & 0,54 & 3,39 \\
22. Annona sp6 & 1,27 & 1,59 & 0 & 2,85 \\
23. Protium paniculatum & 1,27 & 1,59 & 0 & 2,85 \\
24. Virola sebifera & 1,27 & 1,59 & 0 & 2,85 \\
\hline 25. Outras espécies & 16,46 & 20,63 & 12,43 & 49,52 \\
\hline & 100 & 100 & 100 & 300 \\
\hline & & & & \\
\hline & & & & \\
\hline
\end{tabular}

nas depressōes no campo e na floresta, respectivamente. Os dados de $\delta^{13} \mathrm{C}$ da MOS indicaram que no perfil $\mathrm{HO}$ (depressão no campo) ocorreu troca de vegetação durante o Holoceno. No perfil THDF (depressão na floresta) não foi observado troca significativa de vegetação, podendo ter ocorrido no local, em períodos passados, uma vegetação arbórea menos densa ou mistura de plantas $\mathrm{C}_{3} \mathrm{e}_{4}$, com predomínio da primeira.

Os resultados de $\delta^{13} \mathrm{C}$ da MOS e datação ${ }^{14} \mathrm{C}$ da fração humina indicaram que a matéria orgânica de origem $\mathrm{C}_{3} \mathrm{e} \mathrm{C}_{4}$ vem sendo incorporada há, pelo menos, 7.000 anos $\mathrm{AP}$ na área de depressão localizada no ecossistema de campo no km 74. Os resultados de $\delta^{13} \mathrm{C}$ e datação ${ }^{14} \mathrm{C}$ sugerem que no início do Holoceno $(-10.000$ anos AP) a área estudada foi coberta por plantas $\mathrm{C}_{3}$. Entre 7.000-3.000 anos AP, os dados mostraram maior influência de plantas $\mathrm{C}_{4}$, tanto nos perfis de solo da floresta como nos perfís dos campos, indicando uma regressão da floresta associada a um provável clima mais seco que o atual. De 3.000 anos AP até o presente os dados isotópicos indicaram expansão das plantas $\mathrm{C}_{3}$ associada a um provável retorno de um clima mais úmido, semelhante ao atual.

O ecótono de transição floresta-campo na região de estudo caracterizou-se por apresentar três habitats: a floresta com 
$100 \%$ de cobertura arbórea; a borda, uma faixa estreita de 10 a $20 \mathrm{~m}$, com espécies características como a Sclerolobium paniculatum e a Himatanthus sucuuba, e a savana, onde predominaram as gramíneas $\mathrm{C}_{4}$.

Em termos de dinâmica atual de vegetação o avanço da floresta sobre o campo também pode ser observado pelo enriquecimento, no campo, das espécies Sclerolobium paniculatum e Himatanthus sucuuba, que foram espécies mais freqüentes nas bordas da mata e, poderiam estar se expandindo para o campo no $\mathrm{km} 74$. No km 83 não se destacou uma espécie que estaria sendo bioindicadora deste avanço, mas os resultados de $\delta^{13} \mathrm{C}$ da MOS indicaram que houve troca de vegetação na área durante o Holoceno e que atualmente a floresta encontra-se em expansão.

\section{AGRADECIMENTOS}

À FAPESP (01/01151-5) pelo suporte financeiro. À M.V.L. Cruz pelo preparo das amostras. Ao botânico José Eduardo Ribeiro, da Universidade Estadual de Campinas pela colaboração na identificação botânica das espécies amostradas.

\section{BIBLIOGRAFIA CITADA}

Absy, M.L.; Van Der Hammen, T. 1976. Some paleoecological data from Rondônia, Southern part of Amazon Basin. Acta Amazônica, 6(3), 283-299.

Absy, M.L. 1985. Palynology of Amazonia: the history of the forests as revealed by the palynological record. In: Prance, G.T.; Lovejoy, T.E. (Eds) Key environments Amazonia. Oxford: Pergamon Press, p. $72-82$.

Absy, M.L.; Cleef, A.; Fournier, M.; Martin, L.; Servant, M.; Sifeddine, A.; Silva, M.F.; Soubiès, F.; Suguio, K.; Turq, B.; Van Der Hammen, T. 1991. Mise en evidence de quatre d'ouverture de la forêt dense dans le sud-est de I'Amazonie au curs des 60000 dernières années. Premiére comparaison avee d'autres regions tropicales. Compte Rendus de I'Academie des Sciences, 312(2): 673-678.

Behling, H.; Costa, M.L. 2000. Holocene environmental changes from the Rio Curuá record in the Caxiuanã region, eastern Amazon Basin. Quaternary Research, 53, 369-377.

Behling, H.; Costa M.L. 2001. Holocene vegetational and coastal environmental changes from the Lago Crispim record in northeastern Pará State, eastern Amazonia. Review of Palaeobotany and Palynology, 114: 145-155.

Behling, H. 2001. Late Quaternary environmental changes in the Lagoa da Curuça region (eastern Amazonia, Brazil) and evidence of Podocarpus in the Amazon lowland. Vegetation History and Archeobotany, 10: 175-183.

Behling, H.; Keim, G.; Irion, G.; Junk, W.; Mello, J.N. 2001. Holocene environmental changes in the Central Amazon Basin inferred from Lago Calado (Brazil). Palaeogeography, Palaeoclimatology, Palaeoecology, 173: 87-101.
Boulet, R.; Pessenda, L.C.R.; Telles, E.C.C.; Melfi, A.J. 1995. Une evalution de la vitesse de l'accumulation superficielle de matière par la faune du sol à partir de la datation des charbons et de l'humine du sol. Example des latosols des versants du lac Campestre, Salitre, Minas Gerais, Brèsil. Compte Rendus de I'Academie des Sciences, 320(2): 287-294.

Boutton, T.W. Stable carbon isotope ratios of natural materials. II. 1991. Atmospheric, terrestrial, marine, and freshwater environments. In: Coleman, D.C.; Fry, B. (Eds). Carbon isotope techniques. New York: Academic Press. p. 155-171.

Brasil. Departamento Nacional da Produção Mineral. 1978. Projeto Radambrasil. Folha SB 20 Purus. 566pp.

Brower, J.E.; Zar, J.H.; Von Ende, C.N. 1998. Field and laboratory methods for general ecology. 4a. Boston. Ed. WCB. Mc Graw Hill. p. 103-110.

Bush, M.B. 1994. Amazonian speciation: a necessarily complex model. Journal Biogeography, 21: 5-17.

Cerling, T.E.; Quade, J.; Wang, Y. Bowman, J.R. 1989. Carbon isotopes in soils and paleosols as ecology and paleoecology indicators. Nature, 341: 138-139.

Colinvaux, P.A.; de Oliveira, P.E.; Moreno, J.E.; Miller, M.C.; Bush, M.B. 1996. A long pollen record from lowland Amazonia: forest and cooling in glacial times. Science, 27: 55-88.

Colinvaux, P.A.; de Oliveira, P.E; Bush, M.B. 2000. Amazonian and neotropical plant communities on glacial time-scales: The failure of the aridity and refuge hypoteses. Quaternary Science Reviews, 19: 141-169.

Cordeiro, R.C.; Turcq, B.; Suguio, K.; Ribeiro, C.V.; Silva, A.O.; Martin, L.; Sifeddine, A. 1997. Holocene environmental changes in Carajás Region (Para, Brazil) Record by lacustrine deposits. Verh. Internat. Verein Limnol., 26: 814-817.

Cottam, G.; Curtis, J.T. 1956. The use of distance measure in phytosociological sampling. Ecology, 37: 451-460.

Desjardins, T.; Filho, A.C.; Mariotti, A.; Chauvel, A.; Girardin, C. 1996. Changes of the forest-savanna boundary in Brazilian Amazonia during the Holocene as revealed by soil organic carbon isotope ratios. Oecologia, 108: 749-756.

Elias, V.O.; Simoneit, B.R.T.; Cordeiro, R.C.; Turcq, B. 2001. Evaluating levoglucosan as na indicator of biomass burning in Carajás, Amazônia: A comparison to the charcoal Record. Geochimica et Cosmochimica Acta, 65(2): 267-272.

Freitas, H.A.; Pessenda, L.C.R.; Aravena, R.; Gouveia, S.E.M.; Ribeiro, A.S.; Boulet, R. 2001. Late Quaternary vegetation dynamics in the Southern Amazon Basin inferred from carbon isotopes in soil organic matter. Quaternary Research, 55: 3946.

Freitas, H.A. 1999. Estudo da dinâmica de vegetações no sul da Amazônia brasileira no Quaternário recente, utilizando datação por ${ }^{14} \mathrm{C}$ e razão ${ }^{13} \mathrm{C} /{ }^{12} \mathrm{C}$ da matéria orgânica do solo. Dissertação de Mestrado, Universidade de São Paulo, São Paulo. 99pp.

Glenn-Lewis, P.; Peet, R.K.; Veblen, T.T. 1992. Plant sucession: theory and prediction. Chapman and Hall, London.

Gottsberger, G.; Morawetz, W. 1986. Floristc, structural and 
phytogeographical analysis of the savannas of Humaitá (Amazonas). Flora, 178: 41-71.

Gouveia, S.E.M. 1996. Estudo das alterações de paleovegetaçôes na Amazônia central, utilizando a datação radiocarbônica e razão ${ }^{13} \mathrm{C} /{ }^{12} \mathrm{C}$ da matéria orgânica do solo. Dissertação de Mestrado, Universidade de São Paulo, São Paulo. 75pp.

Gouveia, S.E.M.; Pessenda, L.C.R.; Aravena, R.; Boulet, R.; Roveratti, R.; GOMES, B.M. 1997. Dinâmica de vegetaçôes durante o Quaternário recente no sul do Amazonas indicada pelos isótopos do carbono $\left({ }^{12} \mathrm{C},{ }^{13} \mathrm{C}\right.$ e $\left.{ }^{14} \mathrm{C}\right)$. Geochimica Brasiliensis, 11(3): 355-367.

Gouveia, S.E.M.; Pessenda, L.C.R.; Boulet, R.; Aravena, R.; ScheelYbert, R. 1999. Isótopos do carbono dos carvões e da matéria orgânica do solo em estudos de mudança de vegetação e clima no Quaternário e da taxa de formação de solos do estado de São Paulo. Anais da Academia Brasileira de Ciências, 71(4-11): 969-980.

Gouveia, S.E.M.; Pessenda, L.C.R. 2000. Datation per le ${ }^{14} \mathrm{C}$ de charbons inclus dans le sol pour l'étude du rôle de la remontée biologique de matière et du colluvionnement dans la formation de latosols de l'état de São Paulo, Brésil. Comptes Rendus de l'Académie des Sciences. 330: 133-138.

Gouveia, S.E.M.; Pessenda, L.C.R.; Aravena, R.; Boulet, R.; Scheeel-Ybert, R.; Bendassoli, J.A.; Ribeiro, A.S.; Freitas, H.A. 2002. Carbon isotopes in charcoal and soils in studies of paleovegetation and climate changes during the late Pleistocene and the Holocene in the southeast and centerwest regions of Brazil. Global and Planetary Change, 33: 95-106.

Haberle, S.G.; Maslin, M.A. 1999. Late Quaternary vegetation and climate change in the Amazon Basin based on a 50,000 year pollen record from the Amazon Fan, ODP site 932. Quaternary Research, 51: 27-38.

Kiehl, E.J. 1979. Manual de edafologia; relaçôes sololplanta. Agronômica Ceres. 262p.

Kubitzki, K. The dispersal of forest plants. 1985. In: Key environments Amazonia. Eds, Prance \& Lovejoy, Pergamon Press, cap.10, p.192.

Latrubesse, E.; Franzinelli, E. 1993. Reconstrução das condições hidrológicas do passado. Ciência Hoje, 16(93): 40-43.

Ledru, M.P. 1992. Modifications de la végétation du Brésil Central entre la derniére époque glaciaire et l'interglaciaire actuel. Comptes Rendus de l'Académie des Sciences. Paris, 314(2): 117123.

Ledru, M.P. 1993. Late Qauternary and climate changes in Central Brazil. Quaternary Research, 39: 90-98.

Missouri Botanical Garden. 2003. www.mobot.mobot.org/3WT. Acesso (junho de 2003).

Morelato, L.P.C.; Rosa, N.A. 1991. Caracterização de alguns tipos de vegetação na região amazônica, Serra dos Carajás, Pará, Brasil. Revista Brasileira de Botânica, 14(1): 1-14.

New York Botanical Garden, 2003. www.nybg.org. Acesso junho de 2003.

Pessenda, L.C.R.; Gomes, B.M.; Ribeiro, A.S.; Gouveia, S.E.M.; Boulet, R.; Cruz, M.V.L.; Roveratti, R.; Pessin, G. 1996a.
Avaliação de mudanças de vegetação na Amazônia ocidental durante o Holoceno com emprego dos isótopos do carbono do solo. In: Congresso Brasileiro de Geologia, 39., Salvador, 1996. Anais. Salvador, 539-544.

Pessenda, L.C.R.; Aravena, R.; Melfi, A.J.; Telles, E.C.C.; Boulet, R.; Valencia, E.P.E.; Tomazello, M. 1996b. The use of carbon isotopes (C-13, C-14) in soil to evaluate vegetation changes during the Holocene in Central Brazil. Radiocarbon, 38(2): 191-201.

Pessenda, L.C.R.; Valencia, E.P.E.; Camargo, P.B.; Telles, E.C.C.; Martinelli, L.A.; Cerri, C.C.; Aravena, R.; Rozanski, K. 1996 c. Natural radiocarbon measurements in brazilian soils developed on basic rocks. Radiocarbon, 38(2): 203-208.

Pessenda, L.C.R.; Gouveia, S.E.M.; Aravena, R.; Gomes, B.M.; Boulet, R.; Ribeiro, A.S. 1998a. ${ }^{14} \mathrm{C}$ dating and stable carbon isotopes of soil organic matter in forest-savanna boundary areas in Southern Brazilian Amazon Region. Radiocarbon, 40: 1013-1022.

Pessenda, L.C.R.; Gomes, B.M.; Aravena, R.; Ribeiro, A.S.; Boulet, R.; Gouveia, S.E.M. 1998b. The carbon isotope record in soils along a forest-cerrado ecosystem transect: implication for vegetation changes in Rondônia State, southwestern Brazilian Amazon region. The Holocene, 8: 631-635.

Pessenda, L.C.R.; Lisi, C.S; Gouveia, S.E.M.; Datação por ${ }^{14}$ C. 1998c. In: Pessenda, L.C.R. Laboratório de ${ }^{14} C$. Técnicas e aplicação paleoambientais. Piracicaba: CENA/USP, cap.1, p.3-5.

Pessenda, L.C.R.; Valencia, E.P.E.; R.; Aravena, R.; Telles, E.C.C.; Boulet, R. 1998d. Paleoclimate studies in Brazil using carbon isotopes in soils. In: Wasserman, J.C.; Silva-Filho, E.; VillasBoas, R.(eds). Environmental geochemistry in the tropics, Berlin: Springer-Verlag, p.7-16.

Pessenda, L.C.R.; Boulet, R.; Aravena, R.; Rosolen, V.; Gouveia, S.E.M.; Ribeiro, A.S; Lamotte, M. 2001. Origin and dynamics of soil organic matter and vegetation changes during the Holocene in a Forest-savanna transition zone, Brazilian Amazon region. The Holocene, 11(2): 250-254.

Pessenda, L.C.R.; Gouveia, S.E.M.; Aravena, R.; Boulet, R.; Valencia, E.P.E. 2004. Holocene fire and vegetation changes in southeastern Brazil as deduced from fossil charcoal and soil carbon isotopes. Quaternary International, 114: 35-43.

Ribeiro, J.E.L.S.; Hopkins, M.J.G.; Vicentini, A. et al. 1999. Flora da Reserva Duke. Guia de Identificação das Plantas Vasculares de uma Floresta de Terra Firme da Amazônia Central. INPA/ DFID IGA. Manaus. 799pp.

Rosolen, V. 2000. Transformação de uma cobertura laterítica por hidromorfia: estudo de uma toposseqüência da Amazônia brasileira (Humaitá-AM). Tese de Doutorado, Universidade de São Paulo, São Paulo. 201pp.

Sampaio, A. \& Northfleet, A. 1973. Estratigráfica correlação das bacias sedimentares brasileiras. Ann. Congr. Soc. Bras. Geol., 27(3): 189-206.

Sanford, R.L.; Saldarriaga, J.G.; Clark, K.E.; Uhl, C.; Herrera, R. 1985. Amazon rain-forest fires. Science, 227: 53-55.

Santos, G.M.; Gomes, P.R.S.; Anjos, R.M.; Cordeiro, R.C.; Turcq, 
B.J.; Sifeddine, A.; Di Tada, M.L.; Cresswell, R.G.; Fifield, L.K. $2000 .{ }^{14} \mathrm{C}$ AMS dating of fires in the central Amazon rain forest. Nuclear Instruments and Methods in Physics Research, 172: 761-766.

Servant, M.; Fontes, J.C.; Rieu, M. Saliège, J.F. 1981. Phases climatiques arides holocènes dans le sud-ouest de l'Amazonie (Bolivie). Comptes Rendus de l'Académie des Sciences, 292(2), 1295-1297.

Sifeddine, A.; Fröhlich, F.; Fournier, M.; Martin, L.; Servant, M.; Soubiés, F.; Turco, B.; Suguio, K.; Volkmer-Ribeiro, C. 1994. La sédimentation lacustre indicateur de changements des paléoenvironnements au cous des 30000 dernières annèes (Carajas, Amazonie, Brésil). Compte Rendus de I'Academie des Sciences, 318(2): 1645-1652.

Sifeddine, A.; Martin, L.; Turcq, B.; Ribeiro, C.V.; Soubiès, F.; Cordeiro, R.C.; Suguio, K. 2001. Variations of the Amazonian rainforest environment: a sedimentological record covering 30,000 years. Palaeogeography, Palaeoclimatology, Palaeoecology, 168: 221-235.

Sifeddine, A.; Albuquerque, A.L.S.; Ledru, M.-P.; Turcq, B.; Knoppers, B.; Martin, L.; Mello, W.Z.; Passenau, H.; Domingues, J.M.L.; Cordeiro, R.C.; Abrão, J.J.; Bittencourt, A.C.S.P. 2003. A $21.000 \mathrm{cal}$ years paleoclimatic record from Caçó Lake, northern Brazil: evidence from sedimentary and pollen analyses. Palaeogeography, Palaeoclimatology, Palaeoecoloy, 189: 25-34.

Sioli, H. 1985. Amazônia: Fundamentos da ecologia da maior regiāo de florestas tropicais. Petrópolis: Ed. Vozes Ltda. 69pp.
Suguio, K.; Absy, M.L.; Flexor, J.M.; Ledru, M.P.; Martin, L.; Sifeddine, A.; Soubiès, F.; Turq, B.; Ybert, J.P. 1993. The evolution of the continental and coastal environments during the last climatic cycle in Brazil (120 Ky. B.P. to present). Bol. IG-USP, 24: 27-41.

Turcq, B.; Suguio, K.; Martin, L.; Flexor, J.M. 1993. Registros milenares nos sedimentos dos lagos da serra de Carajás. Ciência Hoje, 16(93): 31-35.

Valencia, E.P.E. 1993. Datação por ${ }^{14} \mathrm{C}$ e razão isotópica ${ }^{13} \mathrm{C}^{12} \mathrm{C}$ de solos sob climas tropical e subtropical do Brasil. Dissertação de Mestrado, Universidade de São Paulo, São Paulo. 91pp.

Victoria, R.L.; Fernandes, F.; Martinelli, L.A.; Piccolo, M.C.; Camargo, P.B.; Trumbore, S. 1995. Past vegetation changes in the Brazilian Pantanal arboreal-grassy savanna ecotone by using carbon isotopes in the soil organic matter. Global Change Biology, 1: 165-171.

Vidotto, E. 2003. Estudo da dinâmica do ecótono floresta-campo no sul do estado do Amazonas no Quaternário tardio, empregando os isótopos do carbono do solo e das plantas. Dissertação de Mestrado, Universidade de São Paulo, São Paulo. 101pp.

Whitman, W.C.; Siggeirsson, E.I. 1954. Comparison of line interception and point contact methods in the analysis of mixed grass range vegetation. Ecology, 35(4): 431-436.

Recebido em 06/10/2006

Aceito em 31/07/2007 